\title{
REFLECTOR WIND LOAD CHARACTERISTICS OF THE LARGE ALL-MOVABLE ANTENNA AND ITS EFFECT ON REFLECTOR SURFACE PRECISION
}

\author{
Yan Liu ${ }^{1, *}$, Hong-liang Qian ${ }^{2}$ and Feng Fan ${ }^{2}$ \\ 1 School of Civil Engineering, Chang'an University, Xi'an 710061, P.R. China \\ ${ }^{2}$ School of Civil Engineering, Harbin Institute of Technology, Harbin 150090, P.R. China \\ *(Corresponding author: E-mail: actor_liu@126.com)
}

Received: 23 August 2015; Revised: 19 January 2016; Accepted: 20 February 2016

\begin{abstract}
The wind load could cause the deformation of the reflector surface, seriously affect the resolution and the sensitivity of the antenna and degrade its performance. So the analysis of the wind characteristics of the reflector surface is particularly important. For one thing, the wind loads acting on an open parabolic reflector, as a commonly used type of reflector $(F / D=0.3)$, are obtained by the wind tunnel test and CFD technique and wind characters of the parabolic reflector are revealed. Wind-induced dynamic behaviors under different upwind profiles are also analyzed by the finite element method (FEM). After that based on the numerical simulation, a large number of different kinds of reflectors are researched and analyzed and the results for different diameters, focal length to diameter ratios are acquired to provide sufficient information for wind force proofing design of the antenna structures. Finally, taking the established $110 \mathrm{~m}$ antenna structure as the example and based on the instantaneous pressures derived from the wind tunnel tests, the mechanic performances of the structure at the survival wind speed and working speed are respectively investigated, and consequently the reliability of its mechanic performance is evaluated. The surface RMS of structural responses under various wind loads conditions and internal mechanisms are finally discussed to provide valuable data for the deformation control of the actuators in further work.
\end{abstract}

Keywords: Antenna structure, wind tunnel test, numerical simulation, wind-induced vibration response, wind force proofing design

DOI:10.18057/IJASC.2016.12.4.2

\section{INTRODUCTION}

As a multi-functional, automatic, high-integrated electronic mechanical equipment, the radio telescope structure is subjected to random wind load in the operation of variable-position rotation, which causes the surface deviation of deformed reflector from the theoretical designed reflector. This error has an important influence on the surface accuracy of the reflector [1-3].

For the calculation of wind load, the wind pressure distribution on the reflector surface is required. The influence factors on the distribution are complex and diverse, not only by the wind turbulence in the wind, but also by the wind angle, pitch angle of the antenna structure, the geometrical characteristics of the reflector surface and so on. From the view of the present situation of the domestic application, Miyun 50m antenna in Beijing, Shanghai $65 \mathrm{~m}$ antenna and $110 \mathrm{~m}$ to be built in Xinjiang all belongs to the same category of the all-movable radio telescope which has a focal length to diameter ratio of 0.3 , a circular aperture and parabolic reflector. This situation reflects that the geometric characteristics of the reflector are very common. From the research status of wind force proofing design for the antenna structures, foreign scholars have carried out the wind tunnel test at 4 upwind attitudes for the focal length to diameter ratios 0.5 and 0.25 respectively and acquired the average wind pressure distribution. It can be seen in this achievement the analysis cases for different upwind attitudes are scarce. In domestic the wind tunnel tests study for the focal length to diameter ratio 0.3 with 12 upwind attitudes have been carried out to give the overall drag coefficient of reflector but the average wind pressure distribution of the surface is not given. According to the Load Code for the Design of Building Structures, facing the results achieved, 
although the spherical shell in the geometrical shape is the most close to the parabolic surface, there are still some differences between the two above. Simultaneously the results of the spherical shell derive from the enclosed structure yet the reflector of the antenna in wind field belongs to an open type structure. So the circling flow characteristics around for the two types of structures are quite different.

It can be seen that the research results of this kind of structure are not comprehensive. The comprehension for its wind load and wind induced vibration response characteristics is very poor. It is necessary to carry out a large number of wind tunnel tests and numerical simulations for the reflector structure and provide the meaningful references for the wind load proofing design of the antenna structure and the valuable data for the deformation control of the actuators caused by the wind load.

\section{CFD NUMERICAL SIMULATIONS}

In this work the research objects are different radio telescopes so in the numerical simulation the grid division strategy is significant to solve the FEM [4-7]. The problems need to be done reflect in that the reflector has an open parabolic surface, it is difficult to deal with the grid division around the surface area and not easy to form a high quality grid. So it is intended to make a hybrid mesh for the computational domain. Meanwhile it is necessary to increase the grid around the upper and lower surface, adjust the gradient ratio of the grid and the $y^{+}$value near the surface boundary to further improve the mesh quality and calculation accuracy.

Where, $y^{+}$is introduced to represent the distance from the centroid of the near wall mesh to the wall surface. This dimensionless quantity is related with speed, viscosity and shear stress of the fluid. The specific division is illustrated in section 2.3.

\subsection{Computational Domain Settings}

In the numerical simulation of wind pressure distribution the computational domain is closed by setting several wall surfaces to guarantee the blocking probability is less than $5 \%$. So it is necessary to determine the appropriate computational domain. Computational domain comprises upper reaches $L_{1}$, lower reaches $L_{2}$, windward width $B$, and height $H$. The computational domain is shown in Figure 1 [8-9] and each parameter set is list in Table 1.

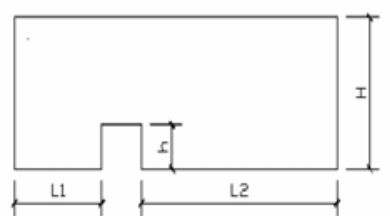

a) Longitudinal section of computational domain

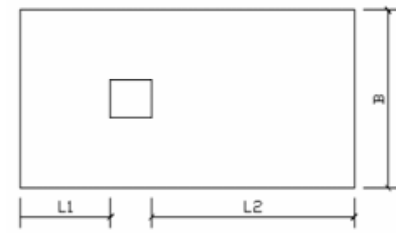

b) Horizontal plane of computational domain Figure 1. Configuration Items of the Computational Domain

Table 1. Computational Field Setting

\begin{tabular}{ccc}
\hline Model size & \multicolumn{1}{c}{$l \times b \times h$} \\
\hline Computational domain & $L_{1}=5 l, L_{2}=15 l, \quad H=8 h, \quad B=10 b$ \\
\hline
\end{tabular}




\subsection{Turbulence Model and Boundary Conditions}

According to the references the complete Reynolds stress model has a relatively high accuracy for solving the flow around a bluff body and its use range is wide. So in this work the RSM turbulence model is used to solve the constant pressure field around a constant flow of the reflector structure. The boundary conditions of the model are set in Table 2 .

\section{$2.3 \quad$ Meshing}

Meshing has a direct influence on the results of numerical simulation and is mainly embodied with the gird size and the grid type. Based on many times in meshing for the flow field around the reflector structure, finally the grid type and grid quantity adopted for each part of the flow field are shown in Table 3 and Figure 2.

1) The outside domain uses the structural hexahedral mesh which could provide a fine grid size, decrease the grid quantity and guarantee the grid quality. While the inside domain uses unstructured tetrahedral grid which could achieve effective meshing to the flow field around the reflector structure.

Table 2. Boundary Condition Setting in CFD

Shear flow is considered: wind profile $V_{z}=V_{10}(z / 10)^{\alpha}$, geomorphic type

B $\alpha=0.15, V_{10}=33.5 \mathrm{~m} / \mathrm{s}$ according to the basic wind pressure.

The governing equations of the incompressible turbulent wind flow around buildings are presented by the RANS equations as follows.

$$
\frac{\partial u_{i}}{\partial x_{i}}=0, \frac{\partial}{\partial x_{j}}\left(\rho u_{j} u_{i}\right)=-\frac{\partial p}{\partial x_{i}}+\frac{\partial}{\partial x_{j}}\left[\mu\left(\frac{\partial u_{i}}{\partial x_{j}}+\frac{\partial u_{j}}{\partial x_{i}}\right)-\rho \overline{u_{i}^{\prime} u_{j}^{\prime}}\right] \text {. }
$$

Inlet boundary Turbulence properties are defined by means of kinetic energy and condition

$$
\text { turbulent dissipation rate. } k=1.5\left(V_{Z} \cdot I\right)^{2}, \quad \varepsilon=\frac{1}{l} 0.09^{\frac{3}{4}} k^{\frac{3}{2}} \text {. Where } l
$$

represents turbulent characteristic scale, and I represents turbulent intensity.

Turbulent intensity of the incoming flow: Refers to data of the second geomorphic type in Australia Code [10-11].

Reference coordinate system: $Y$ axis represents the length direction of the computational domain and $Z$ represents the height direction of the structure.

Outlet $\quad$ Fully developed flow boundary condition is adopted and the normal boundary gradient of any physical quantity $\psi$ in the flow field is zero.

condition

Wall condition

Top and both sides computational domain: free slip wall condition. Reflector surface and ground: no slip wall condition.

2) Because the parabolic reflector has a gradient of spatial curvature and the thickness of the model is only $100 \mathrm{~mm}$. The near wall region adopts the prismatic boundary layer grid to realize the precise control to the meshing and meet the requirements of the minimal wall distance [12-15]. The distance can be characterized by the dimensionless value $y^{+}$which could be expressed in formula (1). The closest grid point near the wall surface is adopted to be $0.025 \mathrm{D}$, with corresponding wall unit $\mathrm{y}^{+}$ranging from about $8 \sim 30$. The determination of $\mathrm{y}^{+}$is controlled and realized by mesh division. 
$y^{+}=\frac{\rho u_{\tau} y}{\mu}$

Where $u_{\tau}$ represents the frictional velocity, $y$ represents the normal distance from the nodes in the first row to the wall surface. $\rho$ represents the air density, and $\mu$ represents the kinematic coefficient of viscosity.

Table 3. Mesh Division for Calculation Area in the Flow Field

\begin{tabular}{cccc}
\hline \multirow{2}{*}{ Model } & Computational domain & Mesh type & Mesh \\
& Outside domain & Structured hexahedral mesh & 1000,000 \\
Parabolic & Inside domain & Unstructured tetrahedral mesh & 500,000 \\
reflector & Near wall region & Prismatic boundary layer mesh & 150,000 \\
\hline
\end{tabular}

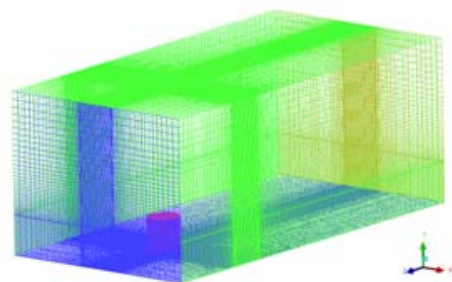

a) Outer calculation domain

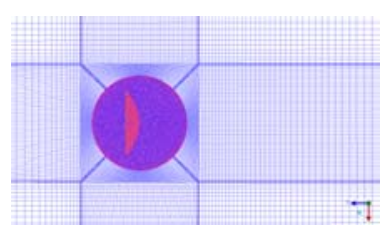

b) Inner calculation domain

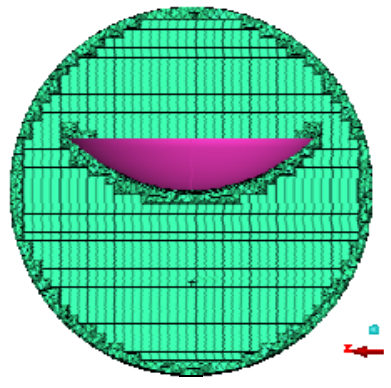

c) Domain of near the wall

Figure 2. Mesh of the Numerical Domain

\section{$2.4 \quad$ Analysis Cases}

The wind direction is defined as shown in Figure 3. According to the symmetry of the model, the wind angle for test is selected about every $30^{\circ}$ in the range of $0^{\circ}$ to $180^{\circ}$. In the pitching rotation the angles of $5^{\circ}, 30^{\circ}, 60^{\circ}$ and $90^{\circ}$ are selected for test. Based on the above parameters there are 22 analysis cases in total (For the pitch angle of $90^{\circ}$, any wind direction is polar symmetrical about the central axis of the reflector so a kind of wind angle is enough).

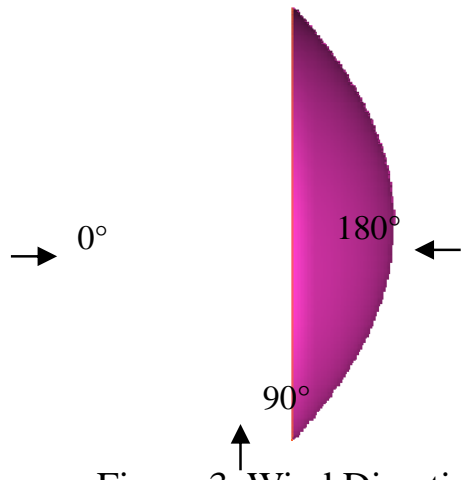

Figure 3. Wind Direction Angle 


\subsection{CFD Simulation Results}

The numerical simulations are carried out by the software Fluent and the average wind pressure distribution on the reflector surface is described in the form of contour by the software Tecplot, shown in Figure 4 to Figure 7. From the figures, under the pitch angle of $5^{\circ}$ for the model, when the wind angle is less than $90^{\circ}$ the reflector surface is completely under the positive pressure and with the increase of the wind angle, the partial pressure coefficient of the edge region increases. When the wind angle is $90^{\circ}$ for the same pitch angle, the negative pressure begins to appear on the reflector surface as the wind suction and the wind pressure distribution along the wind direction is basically symmetrical. The negative pressure area of the reflector surface gradually expands with the increase of the wind angle till the wind angle runs up to $180^{\circ}$, the reflector surface is completely under the negative pressure. When the pitch angle of the model is $30^{\circ}$ or $60^{\circ}$, the wind pressure distribution of the reflector surface is similar to that of the $5^{\circ}$ pitch angle model. In addition, under the same direction with the increase of the pitch angle, the local positive pressure coefficient increases and the distribution area expands. Especially for the pitch angle of $60^{\circ}$ under the wind angle of $60^{\circ}$, the maximum positive pressure coefficient reaches 1.9. The wind pressure distribution on the reflector surface not only has a good symmetry but also shows the maximum negative pressure in the front edge of the windward side for the pitch angle of $90^{\circ}$ under the wind angle of $0^{\circ}$. Meanwhile the absolute value of the negative pressure coefficient gradually decreases and turns to the positive pressure along the flow direction. In the lower reaches the positive pressure begins to increases and the positive pressure area is greater than that of the negative area in general.

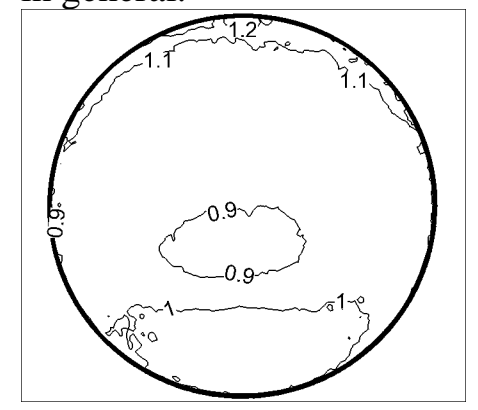

a) $0^{\circ}$

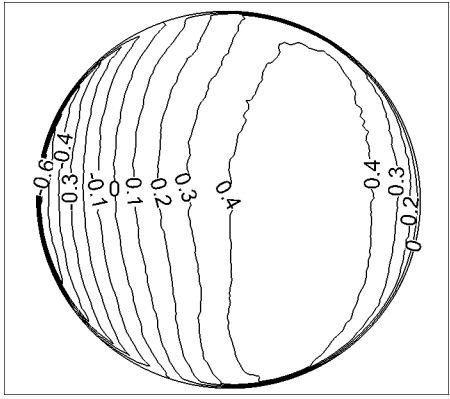

d) $90^{\circ}$

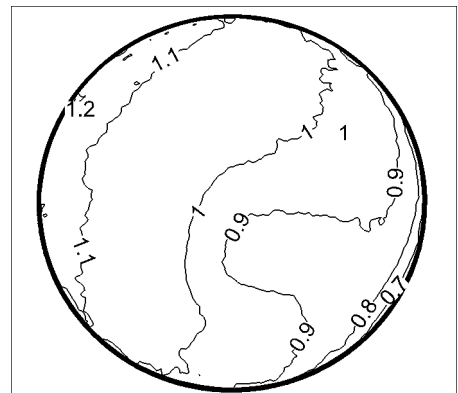

b) $30^{\circ}$

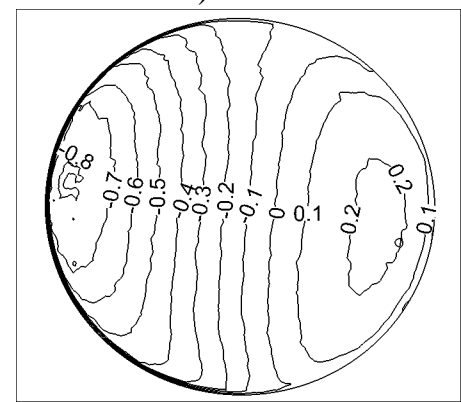

e) $120^{\circ}$

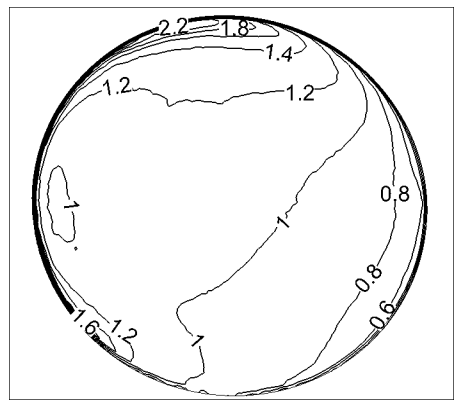

c) $60^{\circ}$

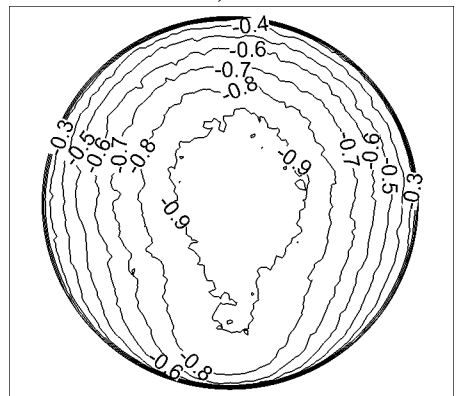

f) $180^{\circ}$

Figure 4. Mean Wind Pressure Coefficients of Reflector under Different Wind Angles for $5^{\circ}$ Pitch Angle 


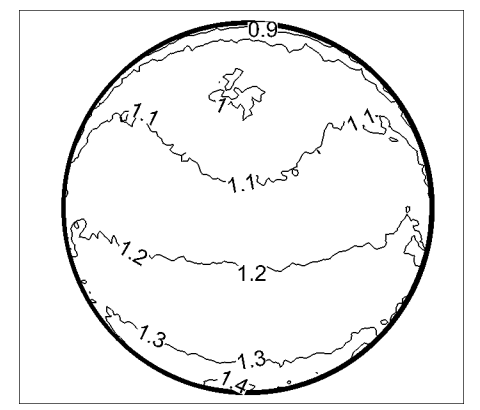

a) $0^{\circ}$

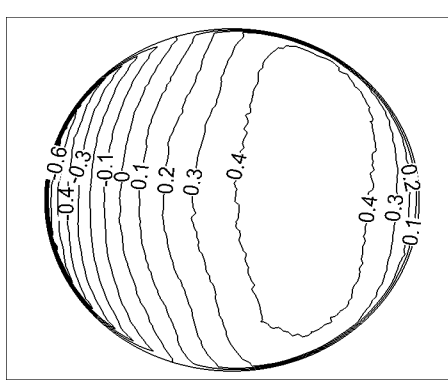

d) $90^{\circ}$

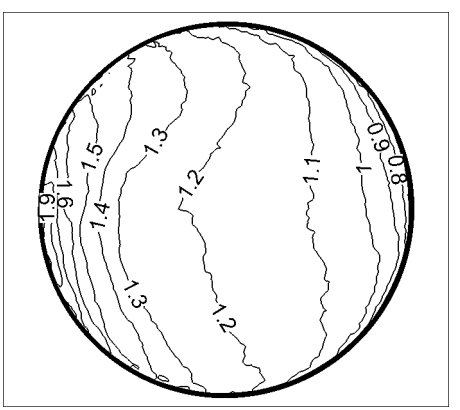

b) $30^{\circ}$

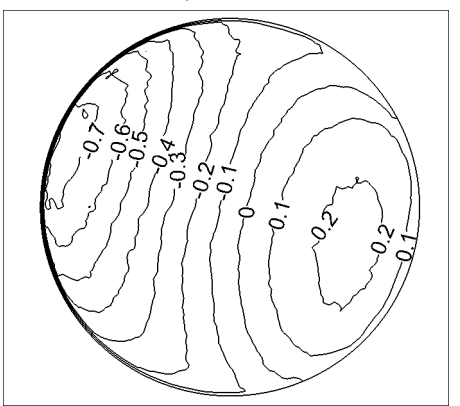

e) $120^{\circ}$

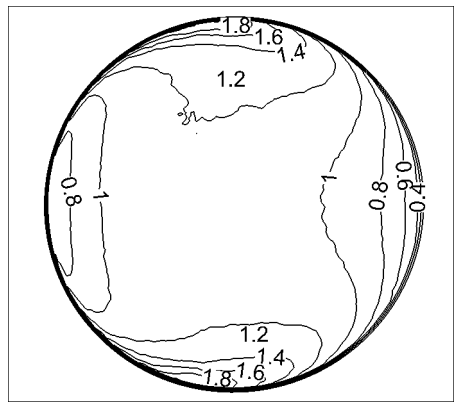

c) $60^{\circ}$

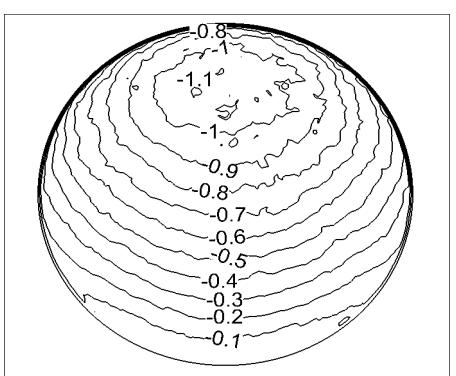

f) $180^{\circ}$

Figure 5. Mean Wind Pressure Coefficients of Reflector under Different Wind Angles for $30^{\circ}$ Pitch Angle

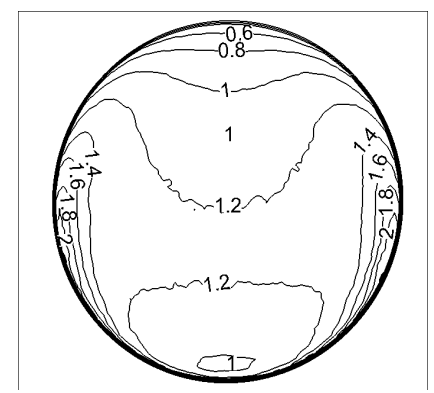

a) $0^{\circ}$

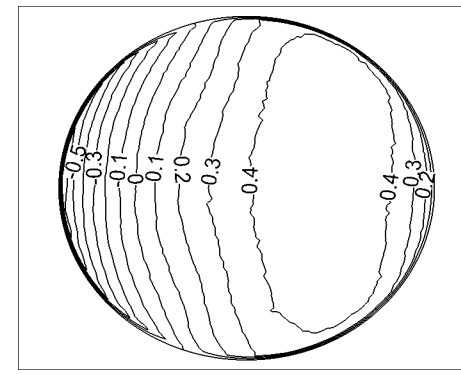

d) $90^{\circ}$

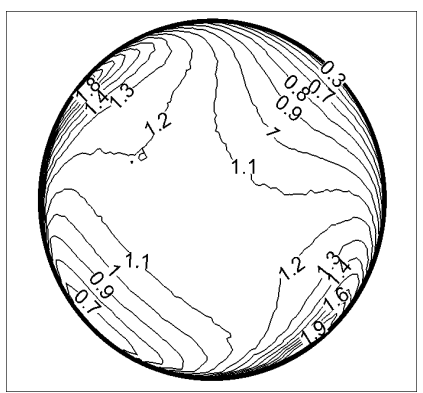

b) $30^{\circ}$

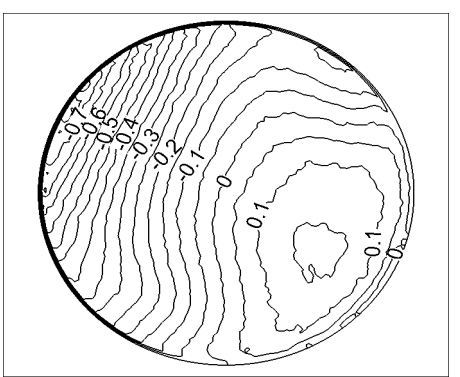

e) $120^{\circ}$

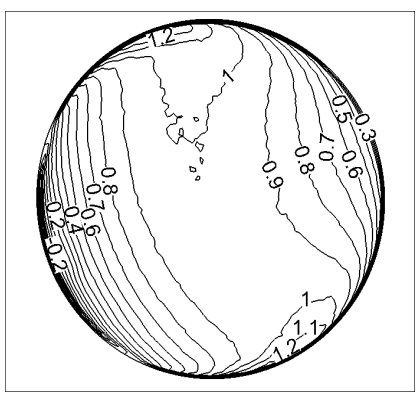

c) $60^{\circ}$

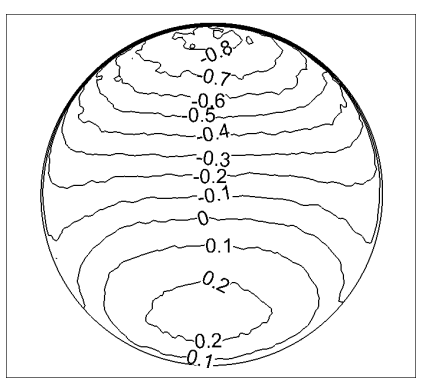

f) $180^{\circ}$

Figure 6. Mean Wind Pressure Coefficients of Reflector under Different Wind Angles for $60^{\circ}$ Pitch Angle 


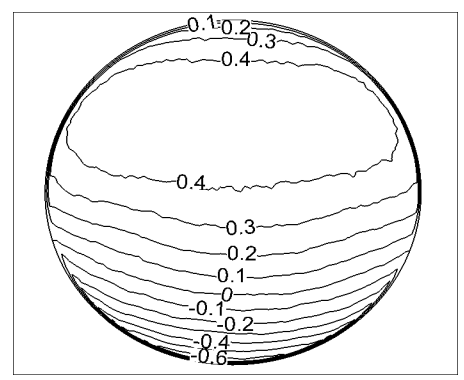

Figure 7. Mean Wind Pressure Coefficients of Reflector for $90^{\circ}$ Pitch Angle

\section{WIND TUNNEL TEST}

In order to verify CFD numerical simulation validity for parabolic reflector structure, scale model test for the $110 \mathrm{~m}(F / D=0.3)$ reflector structure is carried out in the wind tunnel. The test cases concur with the simulation cases and the test is the manometric test of rigid models. By comparison between the test and simulation, the wind pressure characteristics of the parabolic reflector structure are described furtherly and the internal mechanism is revealed.

\subsection{Wind Tunnel Facility and Measurement System}

The manometric test is carried out in the State Key Laboratory for Wind Tunnel and Water flume in Harbin Institute of Technology. The wind tunnel has a double closed test section with the single reflow (shown in Figure 8). The laboratory is a comprehensive experiment platform which integrates the wind field simulation of the near ground surfaces, the deep ocean wave simulation and the rainfall simulation. The small section is $4 \mathrm{~m}$ in width, $3 \mathrm{~m}$ in height and $25 \mathrm{~m}$ in length and the testing wind speed is $3 \mathrm{~m} / \mathrm{s} \sim 50 \mathrm{~m} / \mathrm{s}$. The big section is $6 \mathrm{~m}$ in width, $3.6 \mathrm{~m}$ in height and $50 \mathrm{~m}$ in length and the testing wind speed is $3 \mathrm{~m} / \mathrm{s} \sim 27 \mathrm{~m} / \mathrm{s}$. This work is carried out in the small testing section.

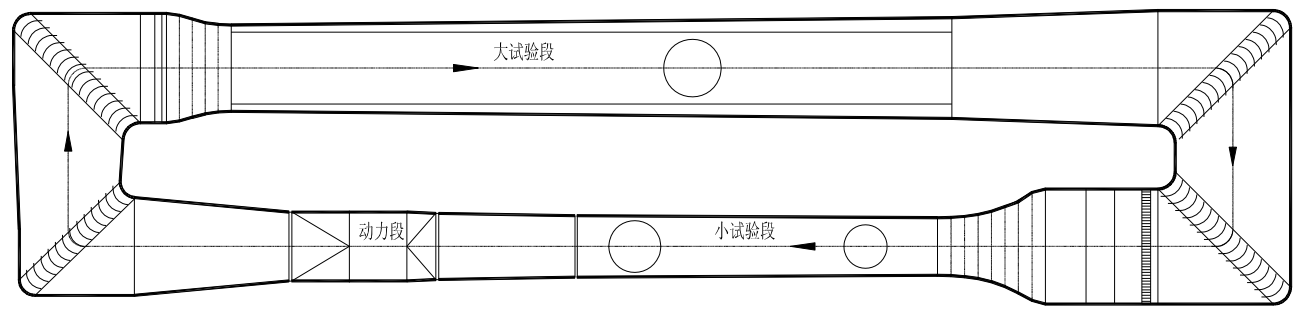

Figure 8. Outline Drawing of Wind Tunnel in HIT

Manometry system uses the electronic pressure scanning valve system produced by Scanivalve scanning company in the USA for scanning and measurement. Finally, the data is recorded and processed by the signal acquisition and data processing software realized in the PC, shown in the Figure 9. 

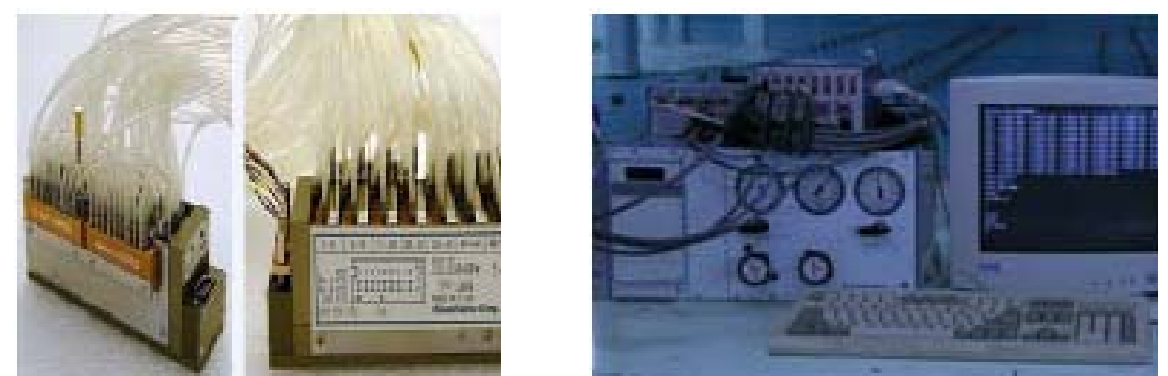

Figure 9. Electronic Pressure Scanner System for DSM3400

\subsection{Simulation of the Atmospheric Boundary Layer}

In the wind tunnel, it is necessary to accurately reproduce the atmospheric boundary layer flow characteristics and ensure credible results. Namely the flow field in the wind tunnel tests should be similar with the atmospheric boundary layer wind flow in the outside world. Its wind speed and turbulence intensity vary with the height. And there are some certain requirements for fluctuating wind power spectrum.

\subsubsection{The mean wind profile}

Below the gradient wind lever, because of the friction near the ground, near-Earth wind speed decreases with the decrease of its height above the ground. The relation between the average wind speed and the height is described as the velocity profile curve. Usually logarithmic and exponential functions are adopted to describe the curve rule. In this paper, exponential law is used as the following formula (2).

$\frac{U_{(Z)}}{U_{r}}=\left(\frac{Z}{Z_{r}}\right)^{\alpha}$

Where $U_{(Z)}$ represents the average wind speed at arbitrary height, $Z$ represents the height, $U_{(r)}$ represents the average wind speed at the standard reference height, $Z_{(r)}$ represents the reference height, $\alpha$ represents the surface roughness index, the structure is situated at a Class B landform and its index value is 0.15 .

\subsubsection{Turbulent intensity}

Turbulence intensity at arbitrary height is expressed as equation (3)

$I_{z}=\sigma_{u}(z) / U(z)$

Turbulence intensity decreases with the increase of the height, usually $20 \% \sim 30 \%$ close to the ground. Chinese specification has no requirement for this at present and the Japanese specification gives specific recommendations about the turbulence intensity.

\subsubsection{The power spectral density function}

Atmospheric turbulence is a random and fluctuating process. The power spectral density function of fluctuating wind velocity is an important parameter to describe the wind field. At present the power spectrums of Davenport, Karman and Kaimal are frequently used in analysis. 
1) Davenport spectrum (based on the Canadian specification NBC and Chinese specification GBJ [16-19])

$\frac{f S_{u}(f)}{\sigma_{u}^{2}}=\frac{4 x^{2}}{6\left(1+x^{2}\right)^{4 / 3}}$

Where $x=f L_{u} / \bar{U}_{10}, f$ represents the frequency, $L_{u}$ represents the turbulence integral scale, approximate to 200 , and $\bar{U}_{10}$ represents the average wind speed at the height of $10 \mathrm{~m}$.

2) Karman spectrum (based on the Japanese specification AIJ )

$\frac{f S_{u}(f)}{\sigma_{u}^{2}}=\frac{4 x}{\left(1+70.8 x^{2}\right)^{5 / 6}}$

Where $x=f L_{u} / \bar{U}_{10}$.

3) Kaimal spectrum (based on the American specification ASCE)

$\frac{f S_{u}(f)}{\sigma_{u}^{2}}=\frac{200 x}{6(1+50 x)^{5 / 3}}$

Where $x=f z / U(z)$.

\subsubsection{Wind field simulation}

In this paper, passive technology is adopted for the simulation of atmospheric boundary layer in the wind tunnel. The concrete geomorphic type is realized with wedge, the bezel and the roughness, shown in Figure $10 \mathrm{a}$ ). The comparison between measured wind speed values and the theoretical spectrum spectral curve is shown in Figure $10 \mathrm{~b}$ ). Its wind speed profile and the turbulence intensity profile are shown in Figure $10 \mathrm{c}$ ) and d) respectively. It obviously that the measured wind speed spectrum in the wind tunnel is the most close to theoretical Karman spectrum.

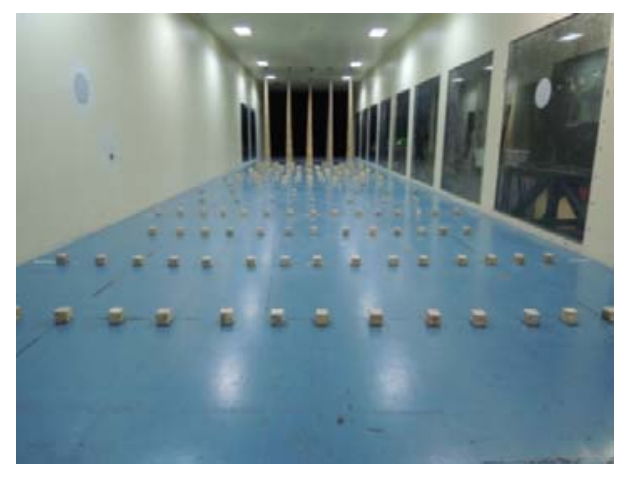

a) Passive simulation device

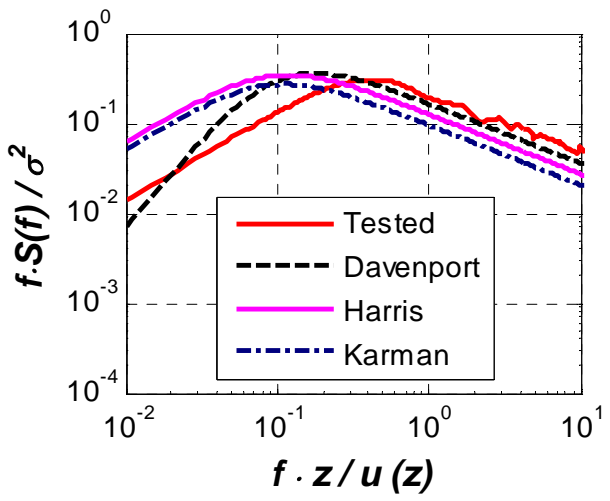

b) Comparison of measurement and theoretical value for wind speed spectrum 


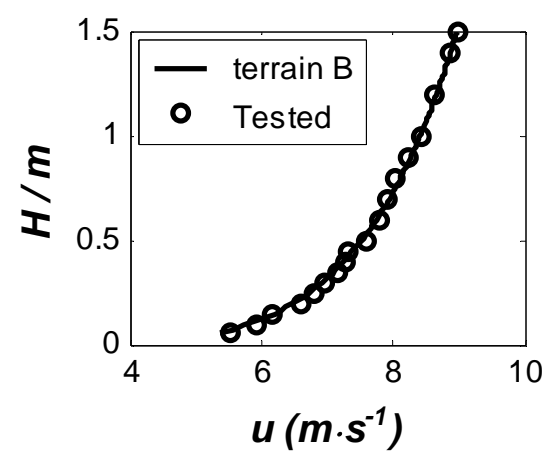

c) Wind profile

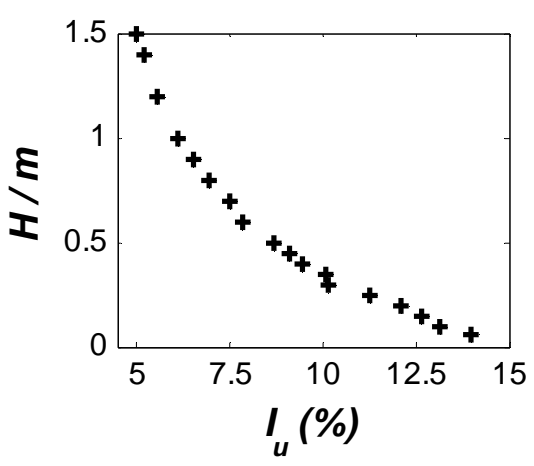

d) Turbulence intensity profile

Figure 10. Wind Tunnel Simulation for Terrain B of the Atmospheric Boundary Layer

\subsection{Test Model and the Procedures Description}

The test model is shown in the Figure 11 . The pitch axis of the lower frame is $250 \mathrm{~mm}$ high off the basement. A series of bolt holes are opened in the lateral and vertical steel pipe on the basis of angular relations to achieve the rotation of the reflector in the pitch direction by arm swing. After each rotation, the lateral and the vertical steel pipes are connected by the corresponding holes to maintain a balance as shown in Figure 12 and 13. In order to acquire not only adequate stiffness and strength of the model, but also facilitation in processing technology, the reflector surface adopts acrylic plexiglass plates. In view of the wind tunnel blockage ratio requirements, the geometry ratio of the model is $1 / 200$. Model has a span of $550 \mathrm{~mm}$ and its ratio of rise to span is 1/4.8. Each acrylic plexiglass plate of two layers has a thickness of $5 \mathrm{~mm}$ and the metal pressure tube has a length of $8 \mathrm{~mm}$. In light of the layout of the pipeline, the minimum interlayer thickness needs $10 \mathrm{~mm}$ space and its size is shown in Figure 14. Convex and concave in the model are arranged by measurement points. Each side has 91 measurement points and these measuring points are shown in Figure 15.

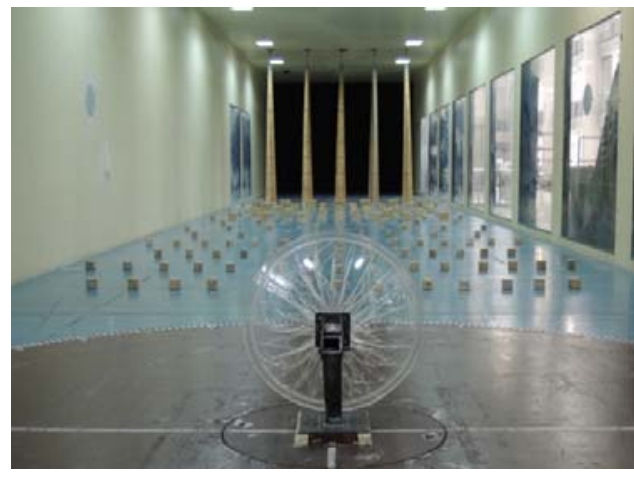

a) Front view

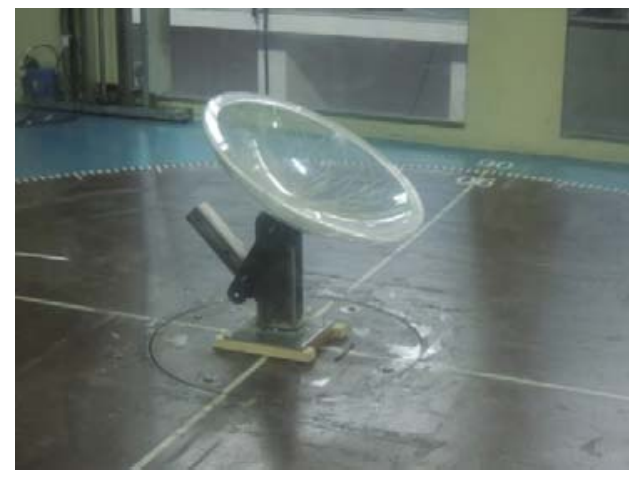

b) Perspective view

Figure 11. Experimental Model in the Wind Tunnel 


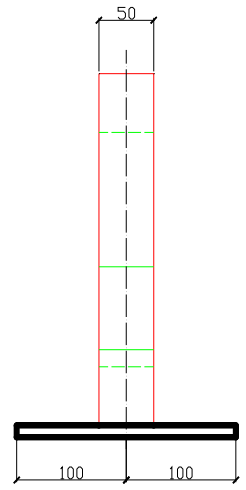

Figure 12. Front View of the Lower Bracket

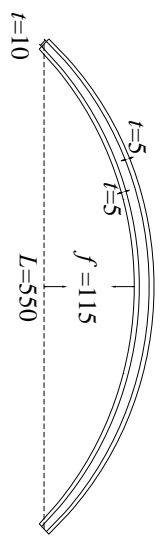

Figure 14. Reflector Section Plan of the Test Model

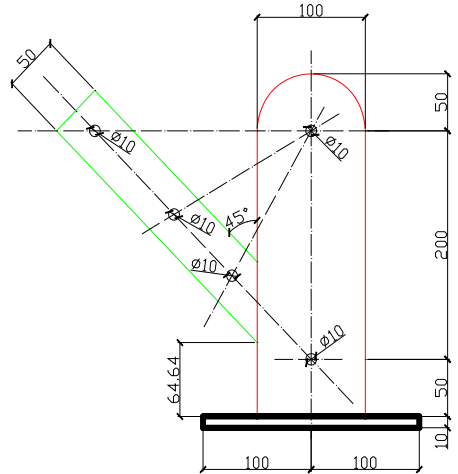

Figure 13. Side View of the Lower Bracket

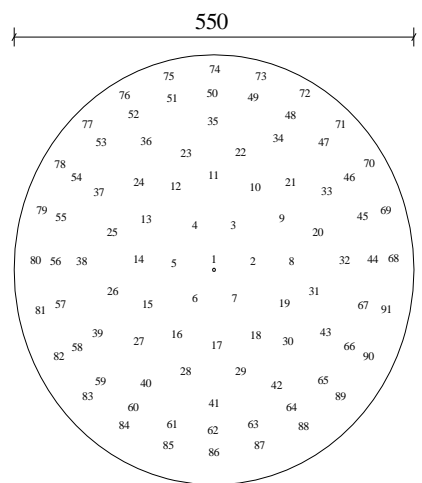

Figure 15. Pressure Tap Arrangement

\subsection{Similarity Ratio Design}

The wind speed in the tunnel is $14 \mathrm{~m} / \mathrm{s}$ and the test speed ratio is $1: 4$. The signal sampling frequency of the pressure valve is $625 \mathrm{~Hz}$ and the sampling duration is 20s. Each individual measurement point collects 12500 times for the data as a sample, five samples in total. According to the similarity theory, the equation (7) shows the relation between the real structure and the test model.

$n_{m} L_{m} / U_{m}=n_{p} L_{p} / U_{p}$

Where $n$ represents the frequency, $L$ represents the geometry size, $U$ represents the wind speed. The subscript $m$ represents the model and $p$ stands for the prototype. It can be obtained from the above equation that $n_{m}=150 \mathrm{~Hz}$. Based on the Naikuitesi sampling criteria, the minimum sampling frequency in the experimental is $150 \mathrm{~Hz} \times 2=300 \mathrm{~Hz}$. It can be concluded that the test sampling frequency $625 \mathrm{~Hz}$ meets the requirements. The similarity ratios of the rest relevant variables are shown in Table 4. In order to obtain reliable experimental data, the final time course of the wind pressure is the average of many samplings.

Table 4. Scaling Laws for Sind Tunnel Tests

\begin{tabular}{cccc}
\hline Clause & Model data & Prototype data & Similarity ratio \\
\hline Diameter & $550 \mathrm{~mm}$ & $110 \mathrm{~m}$ & $1: 200$ \\
Velocity & $14 \mathrm{~m} / \mathrm{s}$ & $56 \mathrm{~m} / \mathrm{s}$ & $1: 4$ \\
Time & $20 \mathrm{~s}$ & $16.6 \mathrm{~min}$ & $1: 50$ \\
\hline
\end{tabular}


The wind pressure value of each measurement point is expressed as the dimensionless pressure coefficient according to the equation (8).

$C_{p i}(t)=\frac{P_{i}(t)-P_{\infty}}{P_{0}-P_{\infty}}$

Where $C_{p i}(t)$ is the pressure coefficient at any hole of the model. $P_{i}(t)$ stands for the measured wind pressure of the structure surface. $P_{0}$ and $P_{\infty}$ represent the average total pressure and the mean static pressure at the reference point respectively. Reference point is the highest point of the reflector surface. For wind-resistant design and comparison with the corresponding specifications, it is necessary to transfer the measured pressure coefficient into the shape factor. For example the relation between the shape factor $\mu_{s i}$ and the average pressure coefficient is expressed as the following equation (9).

$\mu_{s i}=\bar{C}_{p i}\left(\frac{Z_{r}}{Z_{i}}\right)^{2 \alpha}$

Where $Z_{i}$ represents the height of the measuring point, and $Z_{r}$ represents the the height of the standard reference point.

\subsection{Test Results}

Based on the software MATLAB, the corresponding program and the average pressure data contour line drawing process are programmed. The collected process data is processed according to the equation (8). Then the average pressure data is used to make the contour line for all the test conditions as shown in Figure 18 to Figure 21. It can be seen from the figures that when the pitch angle is $5^{\circ}$ and wind angle is within $90^{\circ}$, the reflector surface are completely under the positive pressure, and to the wind angle of $60^{\circ}$, the maximum pressure coefficient is 1.2. When the wind angle is $90^{\circ}$, the negative pressure zone begins to appear at the reflector surface and there is wind suction. When the wind angle is beyond $90^{\circ}$, the reflector surface negative pressure area gradually expands. When the wind angle is $120^{\circ}$, the boundary between the positive and negative pressure zones appears at the centre of the reflector. Until wind angle is $180^{\circ}$, reflective surface is completely controlled by negative pressure. In addition, when pitch angle is $30^{\circ}$ or $60^{\circ}$, contour lines of the pressure distribution are more intensive. It is concretely demonstrated by the edge of the reflector surface where pressure distribution gradient is more intense but the pressure gradient of central area is gentler. When the pitch angle is $90^{\circ}$ and the wind angle is $0^{\circ}$, the reflector surface pressure distribution shows a good symmetry and the maximum wind suction occurs at the windward edge. Along the flow direction, the absolute value of the negative coefficient gradually decreases until the positive pressure appears and gradually increases. Overall the positive pressure area of the reflector surface is bigger than the negative pressure area under the wind load. Nevertheless the negative area mainly focuses on the local region of the windward front of the reflector surface. 


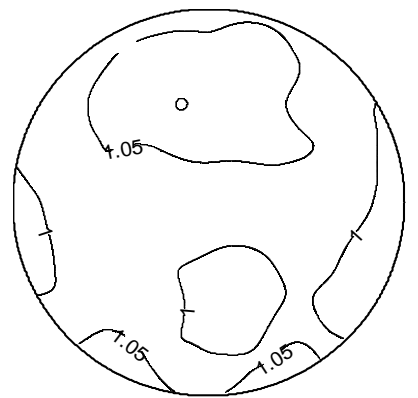

a) $0^{\circ}$

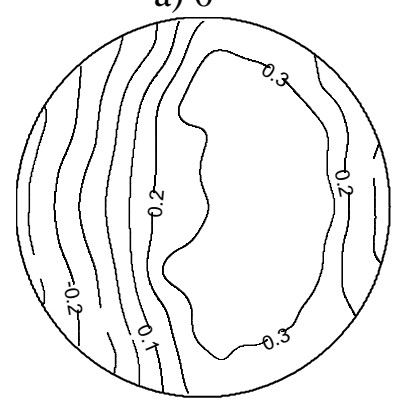

d) $90^{\circ}$

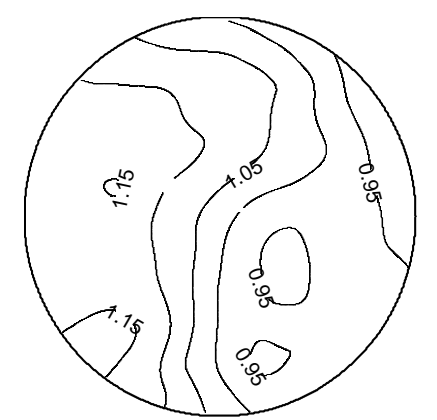

b) $30^{\circ}$

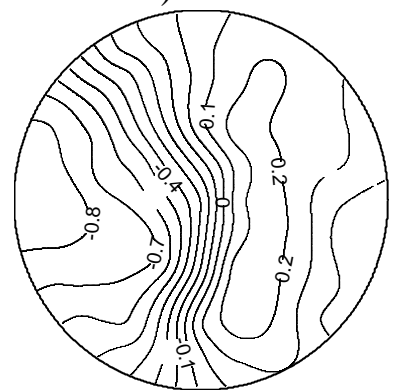

e) $120^{\circ}$

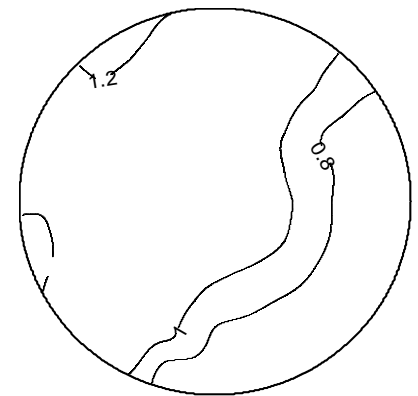

c) $60^{\circ}$

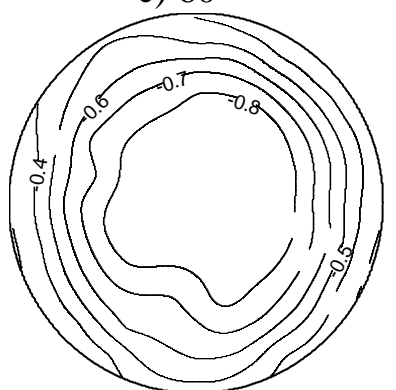

f) $180^{\circ}$

Figure 18. Mean Wind Pressure Coefficients of Reflector in Different Wind Directions for $0^{\circ}$ Pitch Angle

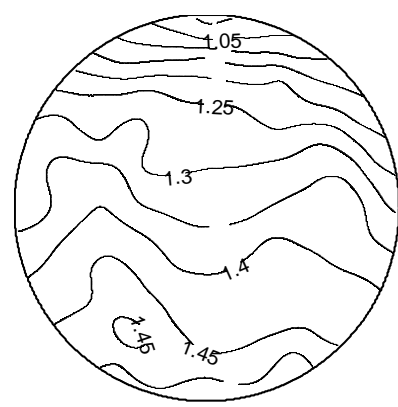

a) $0^{\circ}$

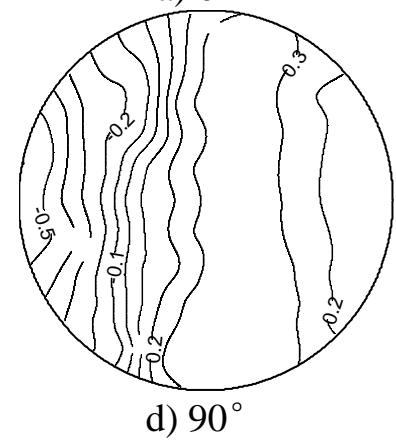

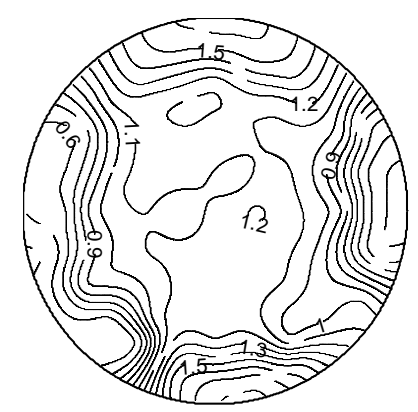

b) $30^{\circ}$

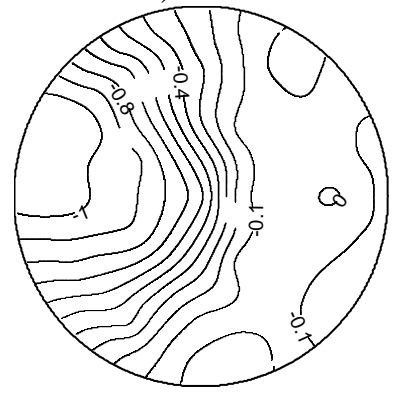

e) $120^{\circ}$

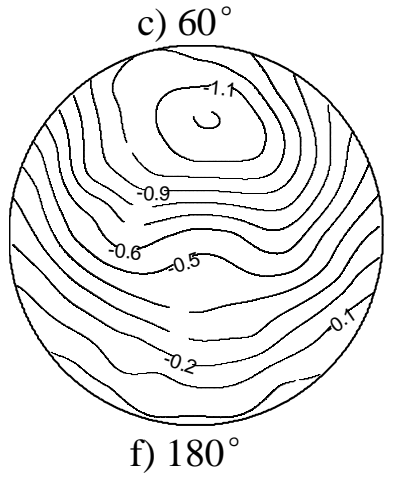

Different Wind Directions for $30^{\circ}$ Pitch Angle 


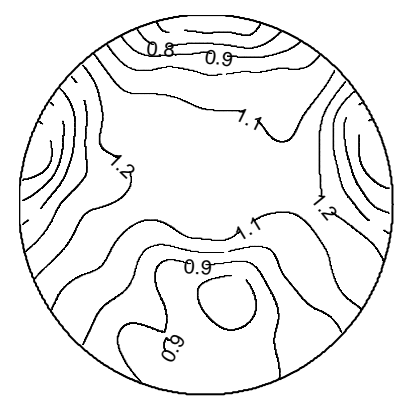

a) $0^{\circ}$

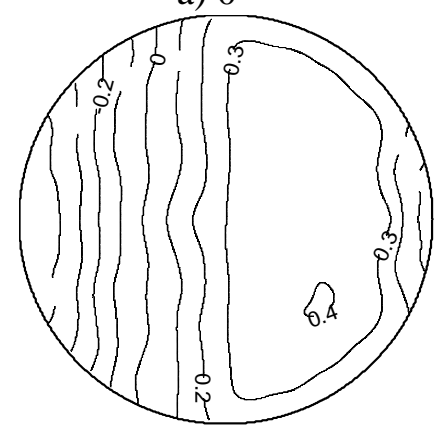

d) $90^{\circ}$

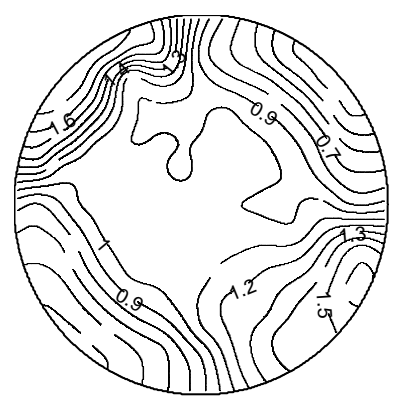

b) $30^{\circ}$

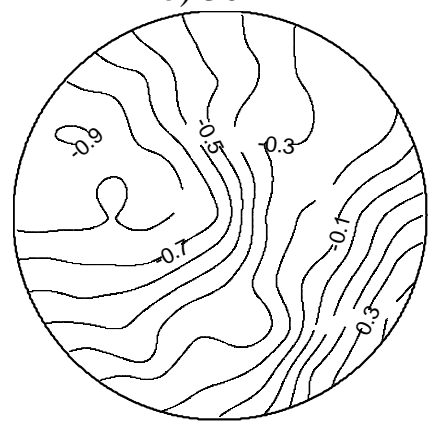

e) $120^{\circ}$

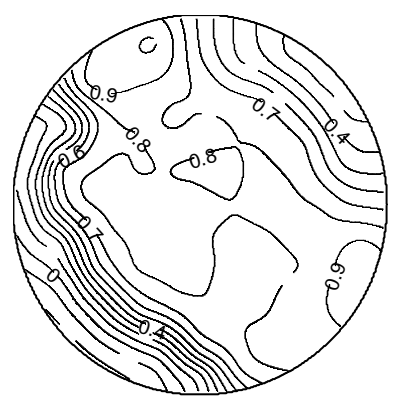

c) $60^{\circ}$

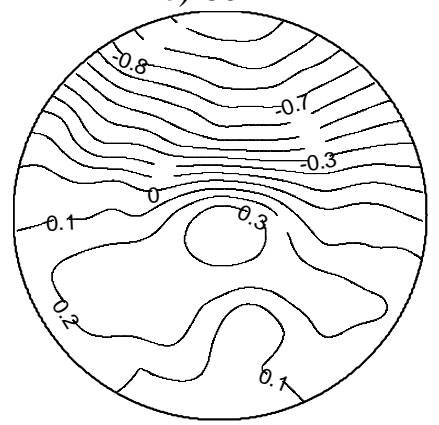

f) $180^{\circ}$

Figure 20. Mean Wind Pressure Coefficients of Reflector in Different Wind Directions for $60^{\circ}$ Pitch Angle

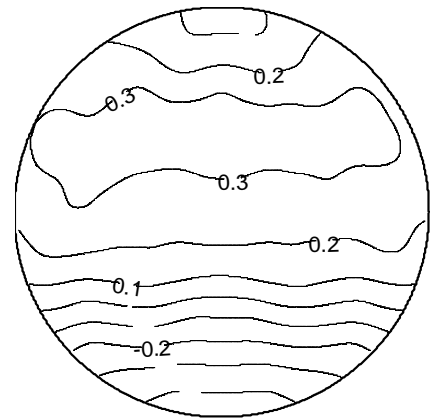

Figure 21. Mean Wind Pressure Coefficients of Reflector for $90^{\circ}$ Pitch Angle

\subsection{Comparison between the Results from Simulation and the Test}

In view of a great deal of test cases, so $0^{\circ}, 90^{\circ}, 180^{\circ}$ in the range of wind angles are selected as typical cases to fully express the gradient variation of the average wind pressure coefficient $\left(C_{\mathrm{p}}\right)$ based on the direction of incoming flow as the symmetrical axis. Figure 22 24 give the comparison of the average wind pressure coefficient between the simulation and the wind tunnel tests. On the whole, under the wind angle $0^{\circ}$, the simulation generally seems to underestimate the pressure coefficients compared to the experimental results. The differences between two approaches are larger than that of two other wind angles. This is mainly under such wind angle, the pressure gradient is so great (wind pressure coefficient varies severely) in the local edge region of the reflector back. This character leads to the difference between the numerical simulation and the test is larger than other wind angles for different pitch angles models, and the contrast effect is not very ideal. As for the wind angle $90^{\circ}$ and $180^{\circ}$, simulation results are slight larger than that of the experiments but then most data are well consonant. This is mainly because the position of separating points for airflow with the wall surface changes significantly which leads to a different wake effect. Specifically for the wind angle $90^{\circ}$, the differences between simulation and test are almost within $8 \%$ and the maximal difference for some individual point reaches $57 \%$ which appears 
at the pitch angle $30^{\circ}$ model. For the wind angle $180^{\circ}$, at each pitch angle model, there are only some single points (just one or two) having the maximal difference which could reaches beyond $50 \%$, but almost the differences from all the data are within $10 \%$. On balance, the results show that the distributions from two research methods above tend to be almost parallel and the data values are well consonant. The results of numerical simulation are well verified by the wind tunnel test. This shows that CFD is a practical and effective method to carry out the wind characteristics analysis to parabolic reflector of the antenna structure.

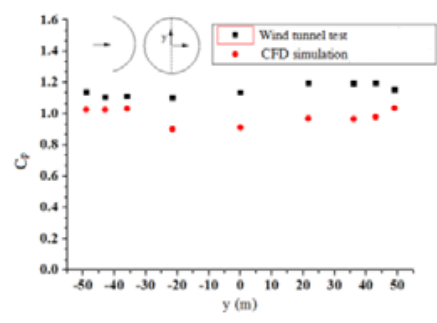

a) $0^{\circ}$ wind angle

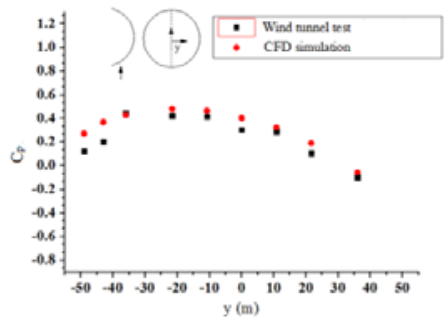

b) $90^{\circ}$ wind angle

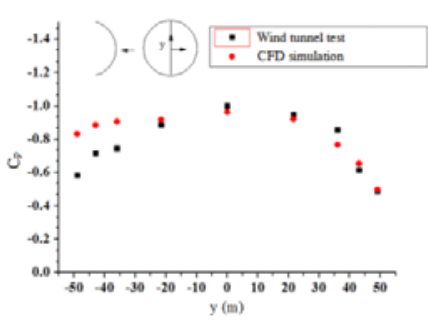

c) $180^{\circ}$ wind angle

Figure 22. Comparison between Numerical Simulated and

Test Results on Reflector at $5^{\circ}$ Pitch Angle

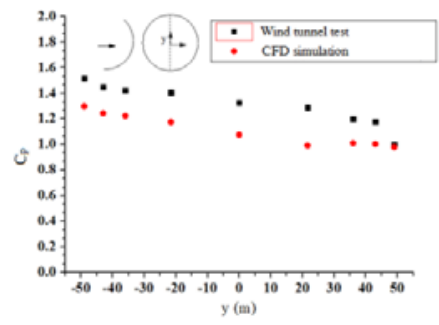

a) $0^{\circ}$ wind angle

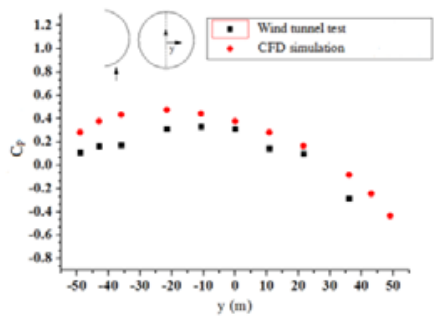

b) $90^{\circ}$ wind angle

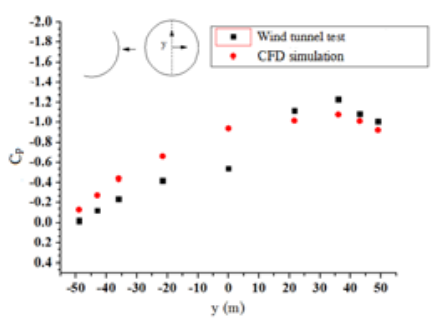

c) $180^{\circ}$ wind angle

Figure 23. Comparison between Numerical Simulated and

Test Results on Reflector at $30^{\circ}$ Pitch Angle

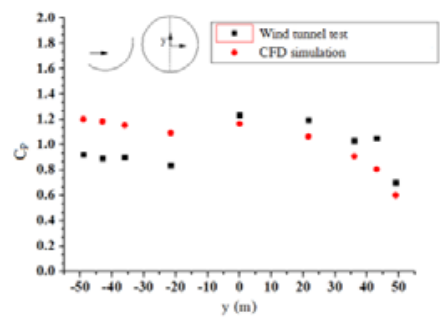

a) $0^{\circ}$ wind angle

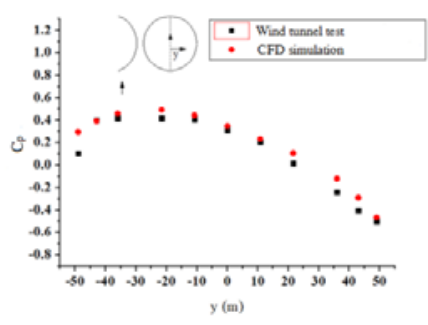

b) $90^{\circ}$ wind angle

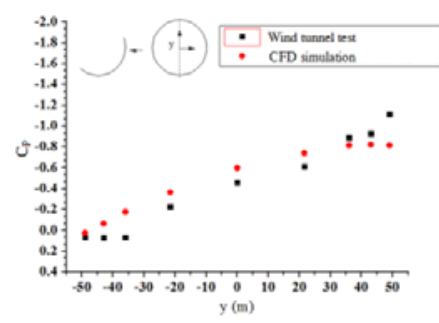

c) $180^{\circ}$ wind angle

Figure 24. Comparison between Numerical Simulated and

Test Results on Reflector at $60^{\circ}$ Pitch Angle 


\section{SHAPE FACTOR OF THE REFLECTOR SURFACE}

Based on the research findings in numerical simulation and wind tunnel test, here in order to acquire the precise wind load for the design of the back frame structure, aiming at different types of reflectors it is necessary to make a partition on the reflector surface and provide the shape factor corresponding with each divided region.

In partition, thanks to the symmetry of the reflector structure, so reflector surface is divided along the ring direction and radial direction according to the formation law of the reflector. Simultaneously in the light of the average wind pressure distribution, the wind pressure gradient of the edge region is large whereas that of the region near the center is relatively flat. So outer ring region is divided densely and inner ring region is divided sparsely. The concrete partition is shown in Figure 25.

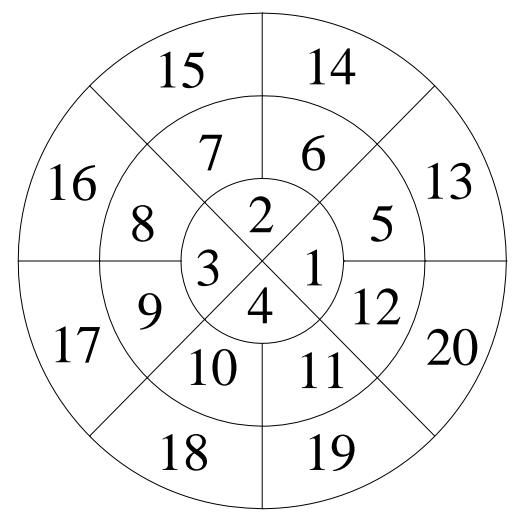

Figure 25. Regional Division of the Telescope Surface

In general, all-movable antenna structures could be classified according to its aperture diameter. The diameters within $50 \mathrm{~m}$ belong to the intermediate region of size and above $100 \mathrm{~m}$ belong to the large span. At present, all-movable antennae within $50 \mathrm{~m}$ are widely distributed throughout the world and the relevant research results constitute a rich harvest. There are about 10 all-movable antennae more or less distributed around the world. Above $100 \mathrm{~m}$ there are only two respectively in the United States and Germany. So on the basis of the current situation, the apertures of $65 \mathrm{~m}$ and $90 \mathrm{~m}$ are selected as illustrating analysis examples in the intermediate region of size meanwhile the aperture of $110 \mathrm{~m}$ is selected as illustrating analysis example in the large span region of size. In addition two kinds of focal length to diameter ratios (0.3 and 0.5 shown in Figure 26) combined with different aperture diameters above are selected as numerical examples to analyze wind field the characteristics by CFD simulation. The obtained mean wind pressure in each node could be calculated and converted into corresponding shape factor according to the formula (9). Finally shape factor for each divided region could be acquired based on the partition in Figure 25 and all computational results are summed up to be shown in Figure 27 32. Based on these 6 figures the shape factor of the reflector surface can be directly found with regard to different diameters, focal length to diameter ratios, pitch angles and wind directions for antenna structures design in the future. 


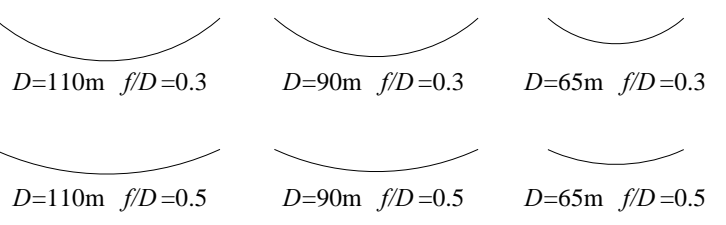

Figure 26. Different Reflector Surfaces

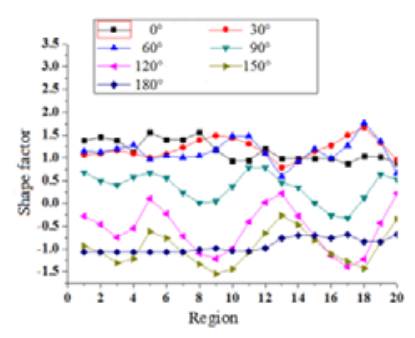

a) $5^{\circ}$

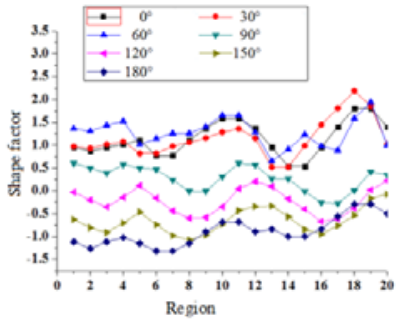

b) $30^{\circ}$

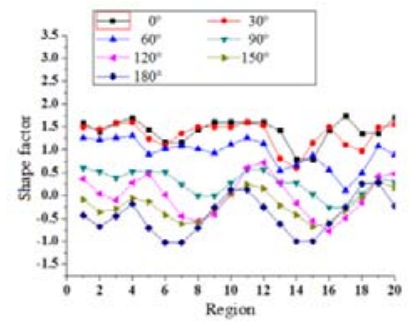

c) $60^{\circ}$

Figure 27. Shape Factor of Wind Load at Different Pitch Angle for 110m Aperture Reflector $(F / D=0.3)$

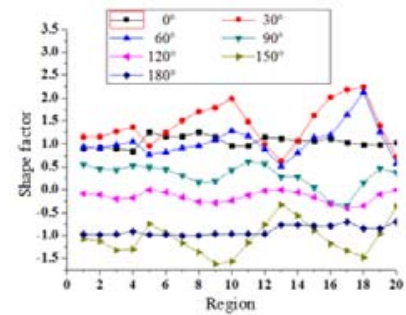

a) $5^{\circ}$

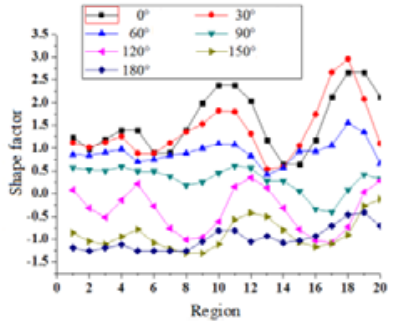

b) $30^{\circ}$

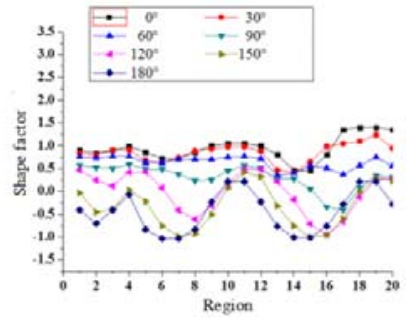

c) $60^{\circ}$

Figure 28. Shape Factor of Wind Load at Different Pitch Angle for 110m Aperture Reflector $(F / D=0.5)$

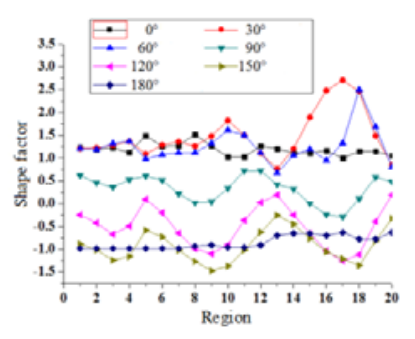

a) $5^{\circ}$

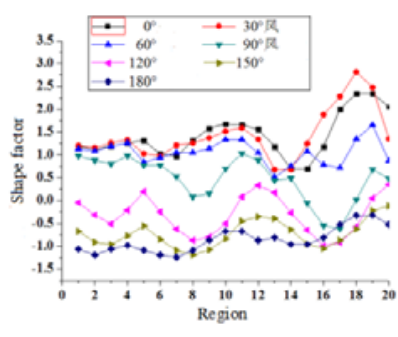

b) $30^{\circ}$

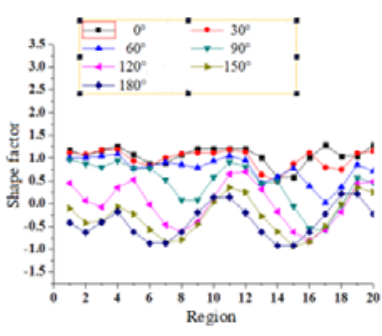

c) $60^{\circ}$

Figure 29. Shape Factor of Wind Load at Different Pitch Angle for 90m Aperture Reflector $(F / D=0.3)$ 


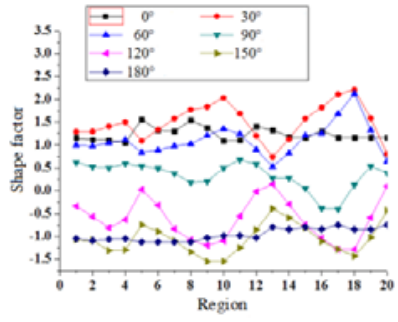

a) $5^{\circ}$

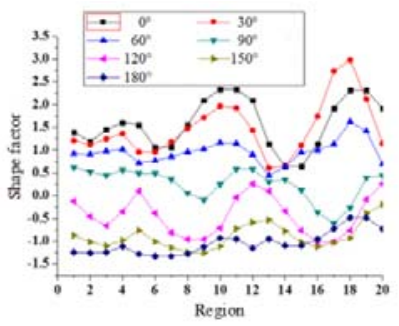

b) $30^{\circ}$

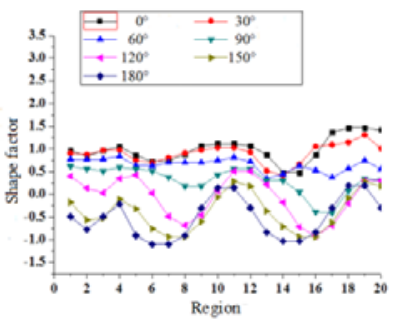

c) $60^{\circ}$

Figure 30. Shape Factor of Wind Load at Different Pitch Angle for 90m Aperture Reflector $(F / D=0.5)$

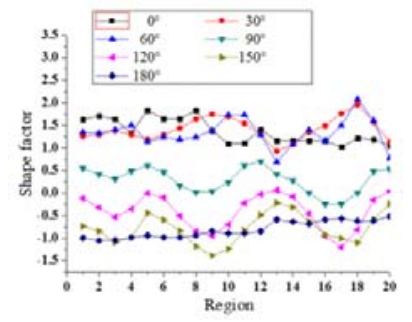

a) $5^{\circ}$

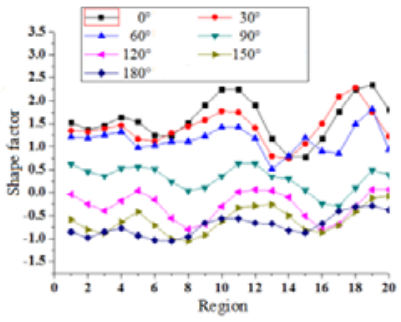

b) $30^{\circ}$

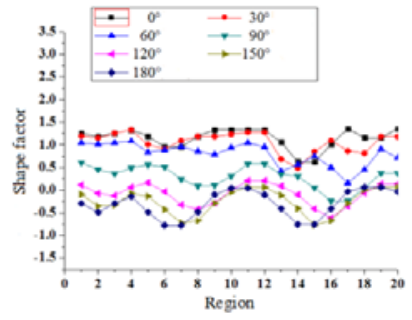

c) $60^{\circ}$

Figure 31. Shape Factor of Wind Load at Different Pitch Angle for 65m Aperture Reflector $(F / D=0.3)$

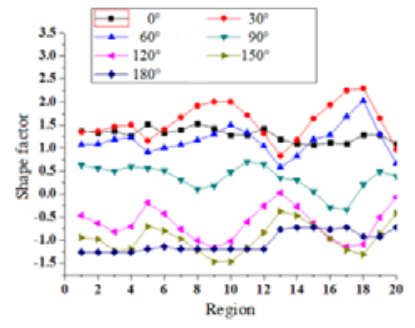

a) $5^{\circ}$

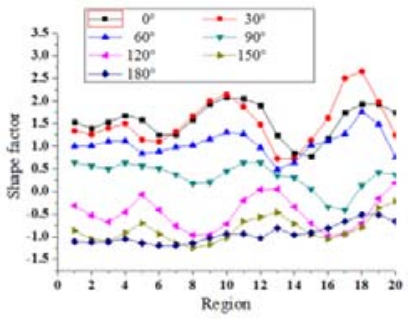

b) $30^{\circ}$

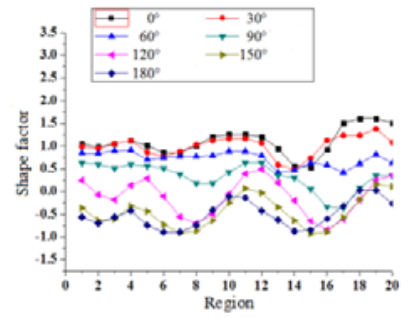

c) $60^{\circ}$

Figure 32. Shape Factor of Wind Load at Different Pitch Angle for 65m Aperture Reflector $(F / D=0.5)$

\section{WIND INDUCED VIBRATION RESPONSE}

The reflector structure of the antenna is a typical large span structure which is not appropriate to use quasi steady assumption under the complex wind load, so it is difficult to estimate the dynamic effect of fluctuating wind. The antenna structure is respectably sensitive to the fluctuating wind in view of its longer natural vibration period and weaker stiffness. Besides dynamic response characteristics for this open type of reflector structure under the fluctuating wind so that it is necessary to furtherly make a dynamic response analysis for the antenna structure based on the time course of wind pressure from the wind tunnel test and probe into the wind induced vibration response of this kind of structure under different pitch angles proposed above. 
The time course of wind pressure obtained from the wind tunnel test is determined according to the similarity ratio relationship between the real structure and the test model, shown in the formula (10).

$(f L / U)_{m}=(f L / U)_{p}$

Where, $f$ represents the frequency, $L$ represents the geometry size, $U$ represents the wind velocity, the subscript $m$ represents test model and $p$ represents the real structure. In the wind tunnel test, sampling frequency is $625 \mathrm{~Hz}$, geometric scaling ratio is $1: 200$, and the wind speed at the height of gradient wind is $14 \mathrm{~m} / \mathrm{s}$ (corresponding to the $56 \mathrm{~m} / \mathrm{s}$ at the actual height of $350 \mathrm{~m}$ ). The basic pressure for the period of 100 years at Qitai County is $0.7 \mathrm{kN} / \mathrm{m}^{2}$.

\subsection{Self Vibration Characteristics Analysis}

The natural frequency is an important parameter to analyze the dynamic response of the structures. In this work the self vibration characteristics are analyzed by subspace iteration method for 4 kinds of typical pitch angles combined with the wind tunnel test. Here taking the model of $90^{\circ}$ pitch angle as an example, from the first 10 order natural frequencies shown in the Table 5 , it can be seen that the frequency distribution of the antenna structure is dense, the frequency of each adjacent mode is very close, the fundamental frequency is low and the structure is more flexible. Due to limited space, Figure 33 gives only first two order modes from which it could be seen that the first order mode is mainly expressed as the rotation of the back frame and the pitching mechanism around the pitch axis, and the second order mode is mainly expressed as the translation of the back frame along the pitch axis with respect to the azimuth pedestal. The remaining modes are mainly expressed as local vibration or torsion of the structure.

Table 5. Ten Order Frequencies of the Telescope Structure

\begin{tabular}{ccccccccccc}
\hline Order & 1 & 2 & 3 & 4 & 5 & 6 & 7 & 8 & 9 & 10 \\
\hline Frequency & 0.887 & 1.032 & 1.158 & 1.214 & 1.358 & 1.545 & 1.681 & 1.843 & 1.972 & 2.125 \\
\hline
\end{tabular}

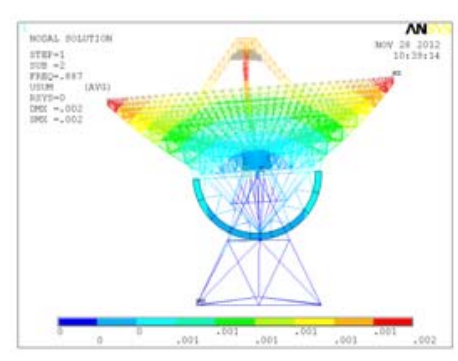

a) The first order

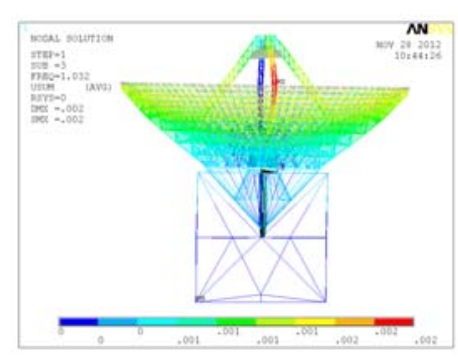

b) The second order

Figure 33. The Mode of Structure Vibration

\subsection{Analysis Method}

The antenna structure is analyzed for the wind-induced response by using nonlinear time-history analysis method. The structure is discretized by using the finite element method and the wind loads are exerted on the corresponding nodes. The structure response is obtained by directly solving the equations of structure motion in the time domain. The calculating results of this method are more realistic than the linear approach in the frequency domain. It could be applied to any system and 
any incentive in principle. And the more complete information about the whole process of structural dynamic response could be got. It is the effective way to analyze the wind induced dynamic response of the antenna structure.

\subsubsection{Wind vibration factor of the displacement and stress}

According to the specification, the dynamic effects of wind load are taken as the static load in the form of wind-induced vibration coefficient. Namely the wind pulse is expressed as the equation (11)

$\beta=\frac{P_{e}}{\bar{P}}=\frac{\bar{P}+P_{d}}{\bar{P}}=1+\frac{P_{d}}{\bar{P}}$

Where $\beta$ is the wind pulse, $P_{e}$ is the equivalent static wind load, $\bar{P}$ is the static wind load, $P_{d}$ is the dynamic wind load.

For the time-history analysis for wind-induced vibration of the complex spatial structure using finite element method, the wind pulse directly bases on the structure response. Namely the wind vibration factor of the displacement and internal force are expressed as the equation (12).

$\beta=\frac{D_{y}}{\overline{D_{y}}}$

The above equation $\bar{D}_{y}$ represents the structural response under the static wind loads, including structural displacement responses and stress responses. $D_{y}$ represents the total extreme wind-induced vibration response of the structure, including static and dynamic response. The relation between them is expressed as the equation (13).

$D_{y}=\bar{D}_{y} \pm g \cdot \operatorname{sign}\left(\bar{D}_{y}\right) \sigma_{y}$

Among them, sign is a sign function, $\sigma_{y}$ is the mean square error of the response for fluctuating wind. $g$ is the peak factor and its value is related with the number of times during which the effect is beyond the average load effect in an average hour. When the probability distribution of the average load effect is normal distribution, $g$ can be expressed according to the equation (14). Where $T$ is the observation time (typically 1 hour), $v$ is the horizontal crossing number, which is in the range from 3.0 to 4.0 , and 3.5 is selected in this paper.

$g=\sqrt{2 \ln v T}+0.577 / \sqrt{2 \ln v T}$

\subsubsection{Whole wind pulse}

The wind pulse of the displacement in each point and of the stress for each element could be obtained according to the equation (15). But for the large span structure, because the spectrum has the intensive modes and the mode contributing a lot may not appear in the first vibration mode, so it is difficult to determine which mode has the significant effect on wind-induced vibration response. In this paper, the wind pulse of the overall displacement and stress based on the maximum dynamic response is used and expressed as the following equation (16). 
$\beta_{d}^{*}=\frac{\left\{\beta_{d i} \times U_{w i}\right\}}{\left\{U_{w i}\right\}_{\text {max }}}$

$\beta_{s}^{*}=\frac{\left\{\beta_{s i} \times S_{w i}\right\}}{\left\{S_{w i}\right\}_{\max }}$

Where $\left\{U_{w i}\right\}$ and $\left\{\beta_{d i} \times U_{w i}\right\}$ are the maximum nodal displacement and time-history displacement respectively under the static wind loads and the total wind loads. Where $\left\{S_{w i}\right\}$ and $\left\{\beta_{s i} \times S_{w i}\right\}$ are the maximum element stress and time-history element stress respectively under the static wind loads and the total wind loads.

\subsection{Vibration Response Results Analysis}

\subsubsection{Analysis scheme and response index}

According to the wind tunnel test results, the overall drag coefficients of the antenna structure under 3 kinds of pitch attitudes are shown in Figure 34, and no matter what pitch angle, the resistance coefficient of $0^{\circ}$ wind angle reaches the maximum value. So the wind angle of $0^{\circ}$ is selected as the analysis condition for wind-induced vibration response analysis respectively under the pitch angle of $5^{\circ}, 30^{\circ}, 60^{\circ}$. Combined with the characteristics of the large span structure and the wind-induced vibration response concerned by the design staff, the normal displacement of each node on the reflector and axial stress + bending stress of the element are used as the indicators of the wind-induced vibration response.

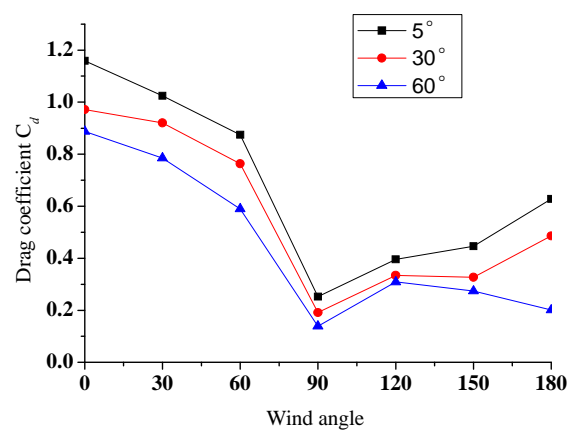

Figure 34. $C_{d}$ in Different Directions

\subsubsection{Results analysis of wind induced vibration response}

Extreme stress and extreme displacement in time-history for the 3 models are shown in Figure 35 and Figure 37. In order to analyze the response characteristics under the fluctuating wind loads in the frequency domain, Fourier transformation is used to convert the response process from the time domain to the frequency domain. The corresponding extreme stress and displacement power spectral density function are shown in Figure 36 and Figure 38. According to the power spectral density function, it can be seen that the wind induced vibration response of the structure is a narrowband process. For the same pitch angle model, the dynamic response from the extreme stress and extreme displacement power spectrum are highly consistent. Combined with the aforementioned natural frequencies of the structure, for the $5^{\circ}$ pitch angle, it is shown that the vibration energy concentrated near the first order frequency $(0.7 \mathrm{~Hz})$ nearby. For the $30^{\circ}$ pitch 
angle, it is still shown that the vibration energy concentrated in the first-order frequency $(0.7 \mathrm{~Hz})$ nearby, nevertheless the amplitude of energy has increased. For the $60^{\circ}$ pitch angle, the higher modes (the third order and the forth order) begin to contribute to the performance of the vibration energy of the structure and from the energy distribution that the peak appear at the frequency of $0.9 \mathrm{~Hz}$ and $1.1 \mathrm{~Hz}$. What's more, the relation between the energy magnitude and the pitch angle shows that the vibration energy increases gradually with the increase of the pitch angle. Later the extreme stress distribution and the displacement distribution of the model are given respectively in Figure 39 and Figure 40. It can be seen in the extreme stress distribution under the wind angle of $0^{\circ}$, the largest stress reaching $170 \mathrm{MPa}$ mainly concentrated in the radius element on the second ring of the upper chord and this condition appears in the model of pitch angle of $30^{\circ}$. It also can be seen from the normal displacement that under the wind angle of $0^{\circ}$, the displacement shows the symmetry along the vertical axis and the extreme displacements of each model appear at the overhangying end and two sides of the reflector surface. In 3 models, the maximal normal displacement is up to $24 \mathrm{~cm}$ and appears in the $5^{\circ}$ pitch angle attitude. Due to space limitations, the calculation results of other models for different pitch angles are shown in Table 6. According to the time-history analysis results, the extreme response for each pitch angle of the antenna structure is determined while the wind pulse for wind force proofing design in the future are provided in Table 6.

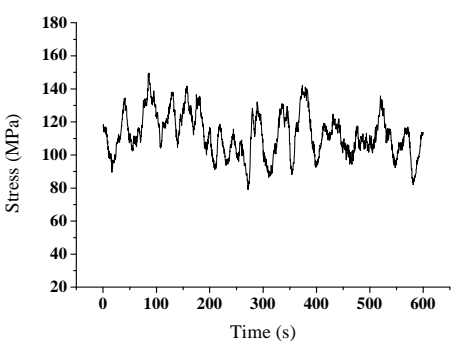

a) $5^{\circ}$

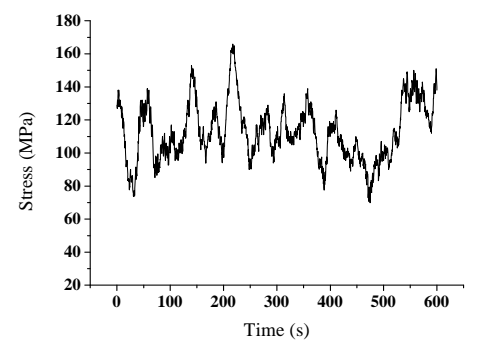

b) $30^{\circ}$

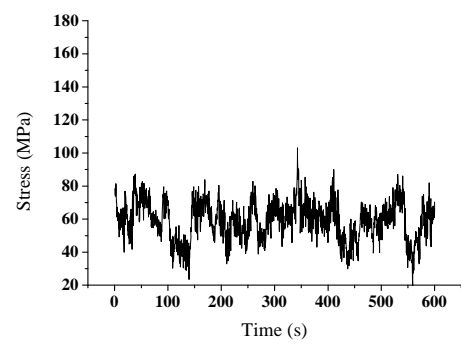

c) $60^{\circ}$

Figure 35. Time-history of the Extreme Stress for Different Kinds of Pitch Angle Models

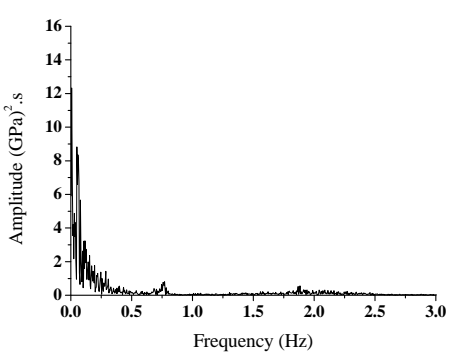

a) $5^{\circ}$

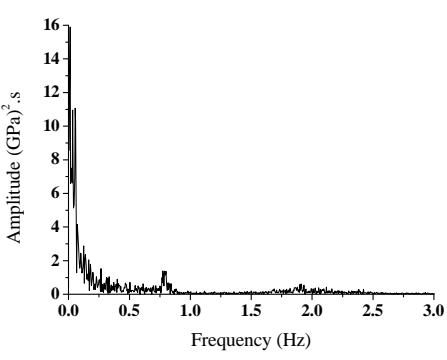

b) $30^{\circ}$

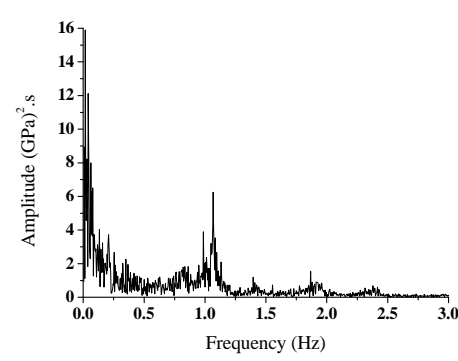

c) $60^{\circ}$

Figure 36. Power Spectral of the Extreme Stress for Different Kinds of Pitch Angle Models

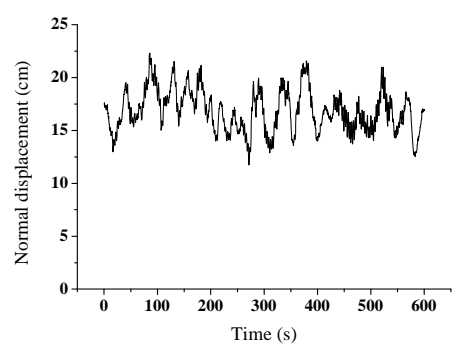

a) $5^{\circ}$

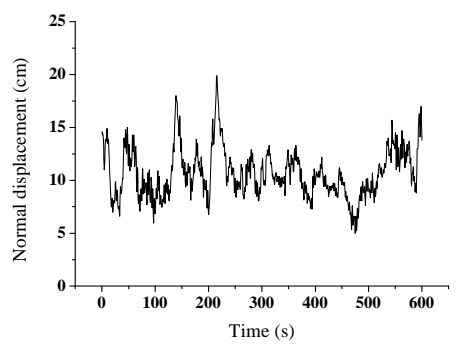

b) $30^{\circ}$

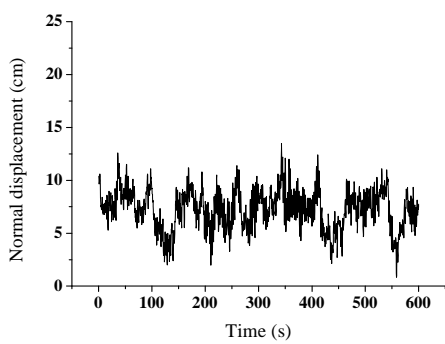

c) $60^{\circ}$

Figure 37. Time-history of the Extreme Displacement for Different Kinds of Pitch Angle Models 


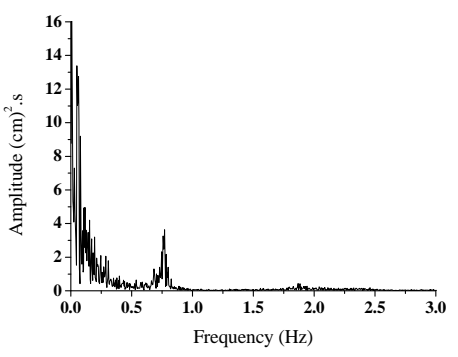

a) $5^{\circ}$

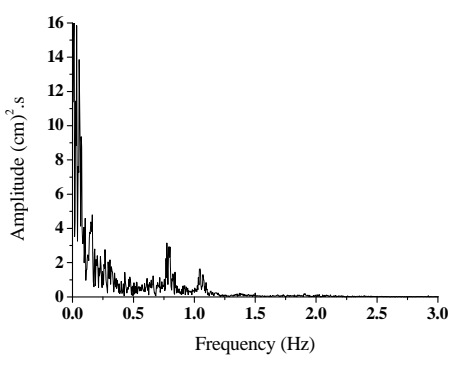

b) $30^{\circ}$

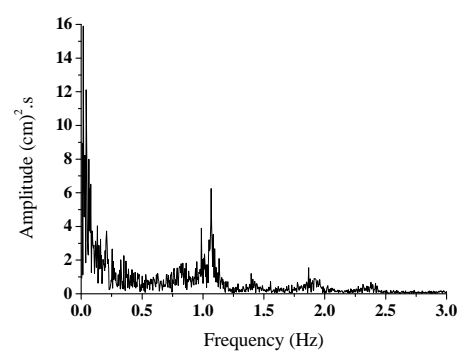

c) $60^{\circ}$

Figure 38. Power Spectral of the Extreme Displacement for Different Kinds of Pitch Angle Models

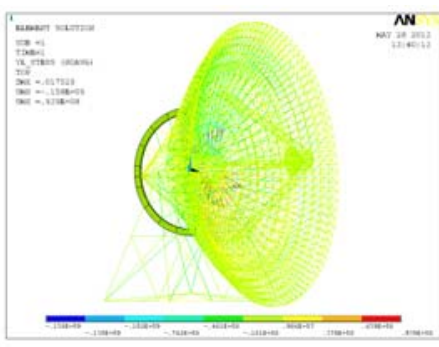

a) $5^{\circ}$

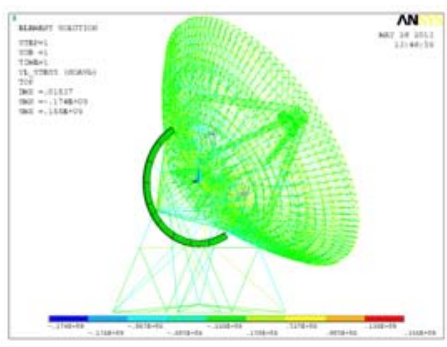

b) $30^{\circ}$

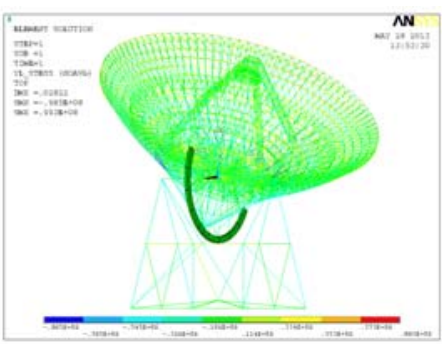

c) $60^{\circ}$

Figure 39. Extreme Value Distribution of Stress for Different Kinds of Pitch Angle Models

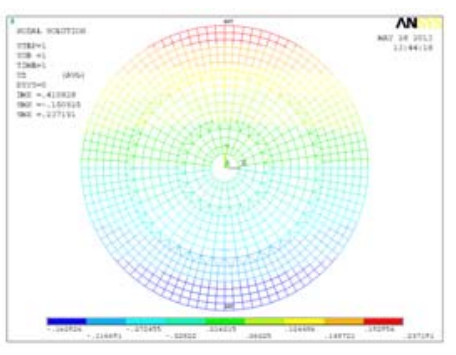

a) $5^{\circ}$

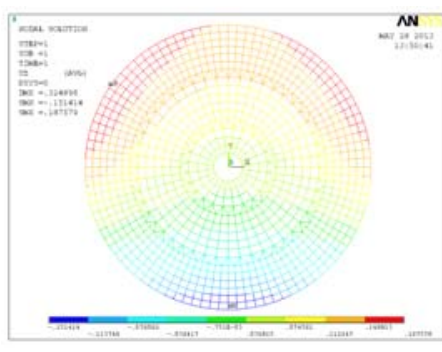

b) $30^{\circ}$

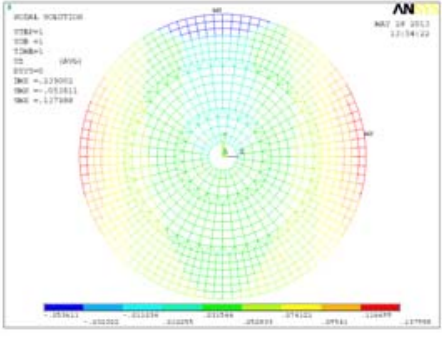

c) $60^{\circ}$

Figure 40. Extreme Value Distribution of Displacement for Different Kinds of Pitch Angle Models

Table 6. Extreme Response and Wind Vibration Factors of the Structure at Different Pitch Angles

\begin{tabular}{ccccc}
\hline Pitch angle & $5^{\circ}$ & $30^{\circ}$ & $60^{\circ}$ & $90^{\circ}$ \\
\hline Maximum displacement & $24 \mathrm{~cm}$ & $19 \mathrm{~cm}$ & $14 \mathrm{~cm}$ & $22 \mathrm{~cm}$ \\
Maximum stress & $158 \mathrm{MPa}$ & $174 \mathrm{MPa}$ & $99 \mathrm{MPa}$ & $152 \mathrm{MPa}$ \\
Whole wind pulse of the displacement & 2.37 & 1.73 & 1.82 & 1.92 \\
Whole wind pulse of the stress & 1.41 & 1.54 & 1.57 & 2.18 \\
\hline
\end{tabular}

\subsubsection{Comment on the nonlinear response of the structure}

According to the analysis of the structural extreme response and power spectral, it can be seen that nonlinear response of the all-movable antenna structure is mainly influenced by the upwind attitudes, and vibration factors are different for different models and structural responses. They are embodied specifically in the followings.

(1) Although the all-movable antenna structure belongs to such kind of rigid structure, its reflector part has a large span up to one hundred meters more or less resulting in that the structure becomes more flexible (this can be inferred by self vibration characteristics analysis). So the effect from 
fluctuating wind could not be neglected in the wind force proofing design and the first four modes of vibration contribute a lot to wind-induced vibration of the whole structure.

(2) From the vibration response results, the whole wind pulse of the displacement is larger than the whole wind pulse of the stress, especially under the pitch angle $5^{\circ}$, because the reflector is almost under the complete upwind state and the top displacement should be focus on. Moreover, although under the pitch angle $5^{\circ}$, the extreme stress is $158 \mathrm{MPa}$ larger than $152 \mathrm{MPa}$ under the pitch angle $90^{\circ}$, the whole wind pulse of stress is 1.41 smaller than 2.18 under the pitch angle $90^{\circ}$. This can be inferred that under the pitch angle $5^{\circ}$, static wind load contribute more than that under the pitch angle $90^{\circ}$. For the model of pitch angle $90^{\circ}$, because wind direction is vertical to the central axis of the reflector, airflow could be separated on the front edge of the reflector and adhere to the end edge again. This phenomenon could form the vortex shedding and severe fluctuating pressure leading to the larger wind pulse.

(3) Under the most unfavorable wind angle $0^{\circ}$, the pitch angles for $5^{\circ}$ and $90^{\circ}$ are two kinds of unfavorable working states because they correspond to the maximal wind pulses of the displacement and the stress respectively. Combined with the wind angle and pitch angle, according to the worst upwind attitude, wind pulses could be determined for the all-movable antenna structure in its whole performance. The whole wind pulse of the displacement could be set as 2.5 and 2.2 could be proper for the stress.

\section{STRUCTURAL ANALYSIS UNDER THE DESIGNED WIND LOAD}

\subsection{Mechanical Analysis under the Survival Wind Speed}

Table 7. Static Combination Conditions

\begin{tabular}{ccccc}
\hline & Combination & $\begin{array}{c}\text { Gravity } \\
\text { coefficient }\end{array}$ & $\begin{array}{c}\text { Snow load } \\
\text { coefficient }\end{array}$ & $\begin{array}{c}\text { Wind load } \\
\text { coefficient }\end{array}$ \\
\hline 1 & Gravity & $1.2 \times 1.0$ & $/$ & $/$ \\
2 & Gravity+wind load 1 & $1.2 \times 1.0$ & $/$ & $1.4 \times 1.0$ \\
3 & Gravity+wind load 2 & $1.2 \times 1.0$ & $/$ & $1.4 \times 1.0$ \\
4 & Gravity+wind load 3 & $1.2 \times 1.0$ & $/$ & $1.4 \times 1.0$ \\
5 & Gravity+snow load & $1.2 \times 1.0$ & $1.4 \times 1.0$ & $/$ \\
6 & Gravity+snow load+wind load 1 & $1.2 \times 1.0$ & $1.4 \times 0.7$ & $1.4 \times 1.0$ \\
7 & Gravity+snow load+wind load 2 & $1.2 \times 1.0$ & $1.4 \times 0.7$ & $1.4 \times 1.0$ \\
8 & Gravity+snow load+wind load 3 & $1.2 \times 1.0$ & $1.4 \times 0.7$ & $1.4 \times 1.0$ \\
\hline
\end{tabular}

For the large antenna structure the member should meet the strength requirement and the deformation need to be limited in the allowable range without collapse under the survival wind $U=40 \mathrm{~m} / \mathrm{s}$. Here the $110 \mathrm{~m}$ antenna structure is selected as a typical object to make the strength and stability analysis under self weight combined with wind load and snow load.

According to the Load Code for the Design of Building Structure combined with the actual environment the antenna structure exists in, the antenna structure is analyzed under the load combination. The load combination is shown in Table 7 and the snow load is considered only for the model of pitch angle $5^{\circ}$. Wind load $1,2,3$, represent $0^{\circ}, 90^{\circ}, 180^{\circ}$ respectively and wind pulse is determined according to the table 6 coming from the wind vibration response analysis. Taking the models of pitch angle $5^{\circ}, 30^{\circ}, 60^{\circ}, 90^{\circ}$, strength and stability analysis is carried on according to the procedures shown in Figure 41. Due to the limited space, only the results from the model of pitch angle $5^{\circ}$ are given in Figure $42 \sim$ Figure 46 and the results for other models are 
generalized in Table 8. These achievements show that under all of the load combinations, the whole structure is in the elastic state, the vast majority of members are in the low stress level within $100 \mathrm{MPa}$ and the maximum deformation is only $128 \mathrm{~mm}$. The value of stress and deformation all meet the relevant specification requirements and the structure is safe.

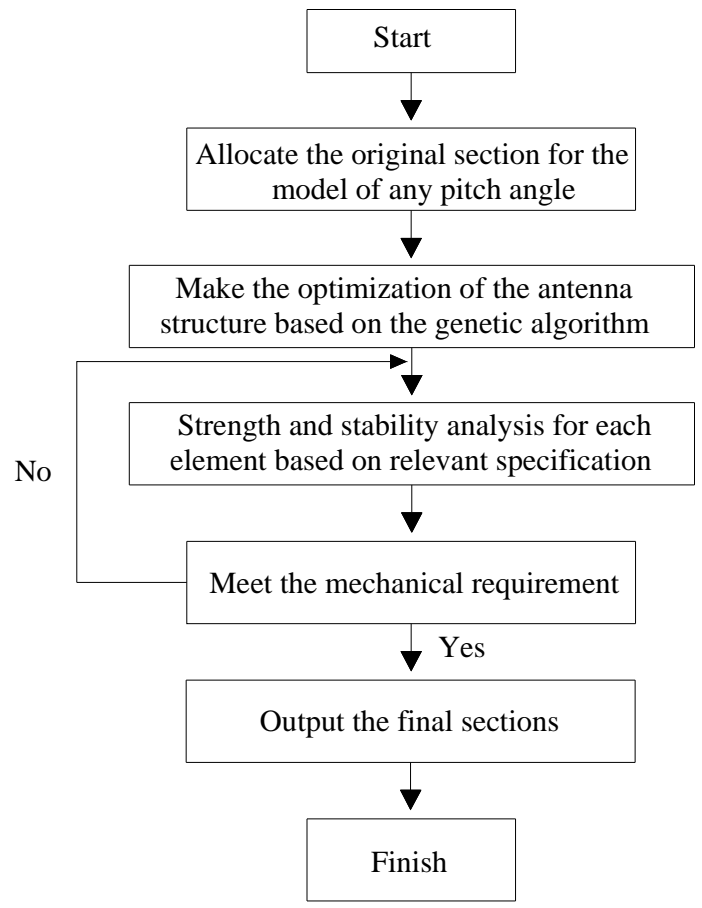

Figure 41. Flowchart of Member Mechanical Performance for the Telescope Structure

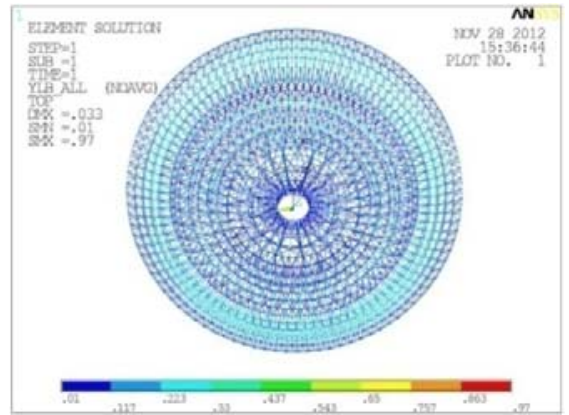

Figure 42. Stress Ratio of Back Frame Structure

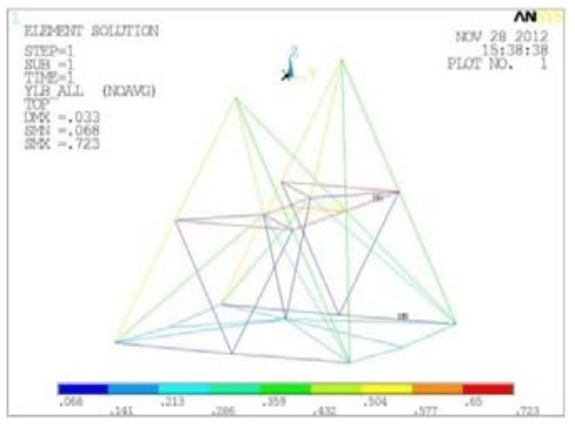

Figure 44. Stress Ratio of Azimuth Holder

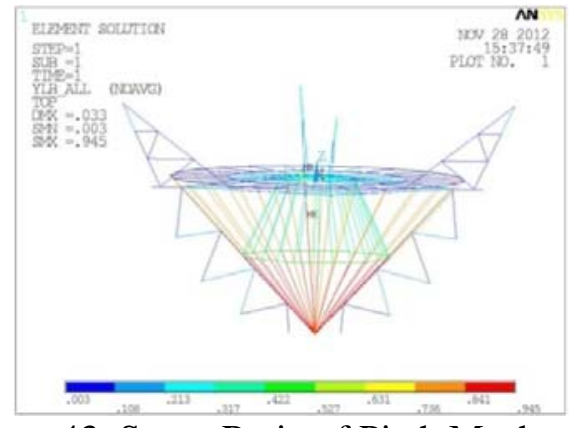

Figure 43. Stress Ratio of Pitch Mechanism

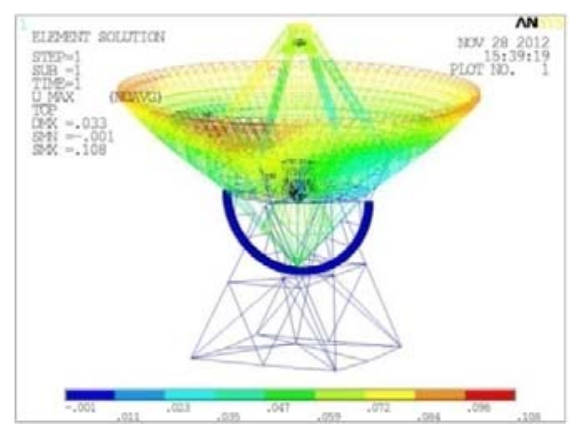

Figure 45. Displacement of the Whole Structure 


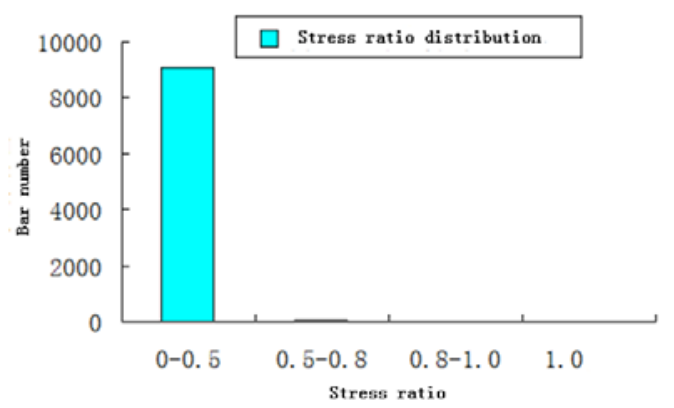

Figure 46. Bar Chart of Stress Ratio for Back Frame Structure

Table 8. Calculating Results of Static Combination Conditions

\begin{tabular}{ccccc}
\hline Pitch angle & Structural response & Back frame & Pitch mechanism & Azimuth mount \\
\hline \multirow{3}{*}{$5^{\circ}$} & Maximum stress ratio & 0.92 & 0.77 & 0.75 \\
& Overrun component & None & None & None \\
& Maximum displacement & & $128 \mathrm{~mm}$ & \\
\multirow{3}{*}{$30^{\circ}$} & Maximum stress ratio & 0.99 & 0.97 & 0.67 \\
& Overrun component & None & None & None \\
& Maximum displacement & & $120 \mathrm{~mm}$ & \\
\multirow{2}{*}{$60^{\circ}$} & Maximum stress ratio & 0.96 & 0.94 & 0.62 \\
& Overrun component & None & None & None \\
& Maximum displacement & & $114 \mathrm{~mm}$ & \\
\multirow{2}{*}{$90^{\circ}$} & Maximum stress ratio & 0.97 & 0.95 & 0.72 \\
& Overrun component & & None & None \\
& Maximum displacement & & $108 \mathrm{~mm}$ & \\
\hline
\end{tabular}

\subsection{Performance Analysis under the Working Wind Speed}

The antenna structure is required to have a good performance under the working speed $U=20 \mathrm{~m} / \mathrm{s}$. That is to say the antenna could still trace the celestial objects and complete the observation mission after the wind deformation is adjusted by the actuators. So it is necessary to make the reflector surface precision analysis under the wind load. Taking the wind angle of $0^{\circ}$ as the typical example, the figure 47 48 give the surface precision RMS and the whole structure displacements for different pitch angles. The surface precision under other wind angles are all given in Table 9 only in the form of data.

\subsubsection{Reflector surface precision analysis under the wind load}

From view of the displacement of the structure, the distribution of the surface deformation is not uniform. For examples, the model of $5^{\circ}$ pitch angle, $0^{\circ}$ wind angle has the maximum displacement on the top and the minimum displacement at the bottom, and the maximum difference reaches $38 \mathrm{~mm}$. The model of $60^{\circ}$ pitch angle, $0^{\circ}$ wind angle has the maximum displacement at the bottom and the minimum value at the center, and the maximum difference reaches $32 \mathrm{~mm}$. For the model of $90^{\circ}$ pitch angle, $0^{\circ}$ wind angle, the maximum displacement appear in the upwind front and thanks to the reflector geometry, in the center of the reflector the displacement reaches the minimum value. These present results are caused by the reflector structure characteristics. In bearing parts of the reflector structure are similar to that of the cantilever roof. With moving on to the inner ring region, the distance to the support region of the reflector structure is much shorter accompanied by the thicker grid height. So the two factors above result in a better stiffness and the displacement naturally decreases in the region near the center of the reflector. Simultaneously 
combined with the results in section 2 3, near the edge of the reflector extreme wind pressure often appears and the pressure gradient is more intense. By contraries, near the center zone of the reflector, the wind pressure gradient is gentler and the stress is naturally more uniform. So in view of the stress condition and the stiffness distribution of the reflector structure, it is inevitable that the reflector surface deforms unevenly and has an undesirable precision.

Table 9. RMS of Reflector Surface under the Wind Load

\begin{tabular}{lcccc}
\hline Pitch angle & Wind angle & $0^{\circ}$ & $90^{\circ}$ & $180^{\circ}$ \\
\hline $5^{\circ}$ & 0.362 & 2.092 & 0.212 \\
& $30^{\circ}$ & 2.206 & 1.715 & 0.377 \\
$60^{\circ}$ & 2.102 & 1.785 & 0.586 \\
& $90^{\circ}$ & 2.096 & 2.092 & 2.103 \\
\hline
\end{tabular}

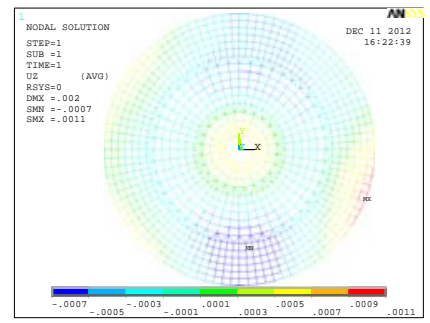

a) $5^{\circ}$

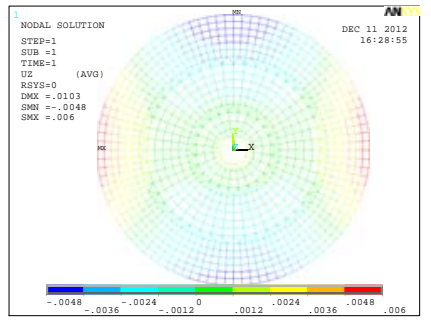

b) $60^{\circ}$

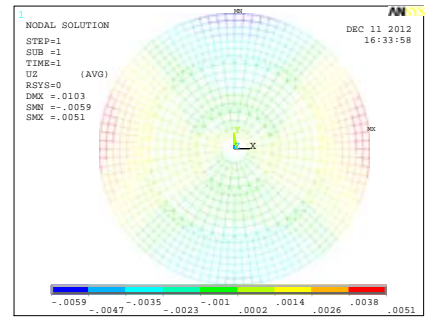

c) $90^{\circ}$

Figure 47. Half Optical Path Error of Reflector Surface

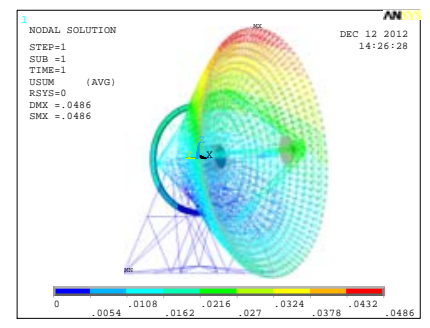

a) $5^{\circ}$

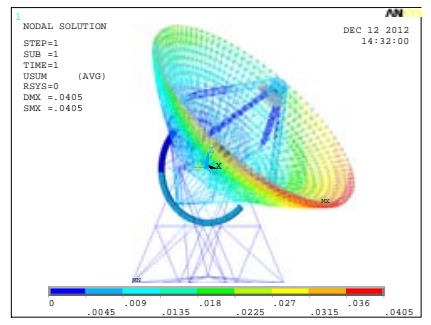

b) $60^{\circ}$

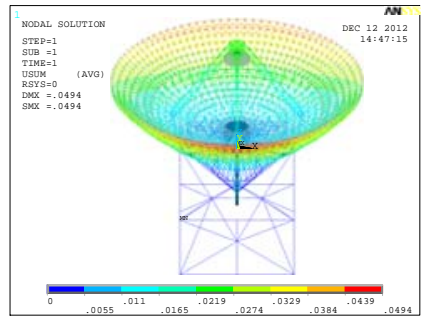

c) $90^{\circ}$

Figure 48. Whole Displacement of the Structure

\subsubsection{Surface precision analysis for different models under different load cases}

In the actual operations, it is necessary to calculate the influence of not only single load but also the combination of different loads because the gravity load coexists with the wind load, and pay special attention to the leading factor. Table 10 gives the reflector surface precision under different load cases. Limitations of space allows for the results of $0^{\circ}$ wind angle if wind load joins in the combination.

From the table above it is obviously that the wind load has a greater effect than gravity load on the reflector surface precision. On the one hand, the structure is more flexible and sensitive to the wind load with the increase of the aperture diameter. Compared with gravity load wind load has a more serious effect and plays a leading role. On the other hand, in the antenna structure scheme approachment, the lectotype and the optimization mainly consider the gravity load that is to say the back frame structure style is determined and the section of each pipe is optimized under the gravity 
load effect. So in order to realize a high reflector surface precision the back frame structure obtains a reasonable stiffness distribution in such a scheme determination course. Namely some part has more weights, more stiffness will appear, vice versa. But from the deformation under the wind load shown in Figure 48, the stress caused by wind load could not fit with the structure stiffness so the deformation heterogeneity caused by wind load is more seriously than that of the gravity load which results in a lower surface precision under the single wind load or the combination the wind load joins in.

Table 10. Surface Precision on Main Reflector under Each Working Condition (RMS)

\begin{tabular}{ccccc}
\hline \multicolumn{5}{c}{ Gravity effect } \\
\hline Pitch angle & $5^{\circ}$ & $30^{\circ}$ & $60^{\circ}$ & $90^{\circ}$ \\
Surface precision & $0.306 \mathrm{~mm}$ & $0.223 \mathrm{~mm}$ & $0.143 \mathrm{~mm}$ & $0.306 \mathrm{~mm}$ \\
\hline \multicolumn{5}{c}{ Wind load effect } \\
\hline Wind velocity & $5^{\circ}$ & $30^{\circ}$ & $60^{\circ}$ & $90^{\circ}$ \\
Pitch angle & $0.362 \mathrm{~mm}$ & $2.206 \mathrm{~mm}$ & $2.102 \mathrm{~mm}$ & $2.096 \mathrm{~mm}$ \\
Surface precision & \multicolumn{5}{c}{$20 \mathrm{~m} / \mathrm{s}$} \\
\hline Effect of the combination of gravity and wind load \\
\hline Wind velocity \\
Pitch angle & $5^{\circ}$ & $30^{\circ}$ & $60^{\circ}$ & $90^{\circ}$ \\
Surface precision & $0.175 \mathrm{~mm}$ & $2.265 \mathrm{~mm}$ & $2.342 \mathrm{~mm}$ & $2.259 \mathrm{~mm}$ \\
\hline \multicolumn{4}{c}{}
\end{tabular}

\section{CONCLUSIONS}

The widely used parabolic reflector $(F / D=0.3)$ is selected as an analysis point of penetration to carry out the numerical simulation for its 22 kinds of gestures. Subsequently, the manometry tests are carried out in the wind tunnel for the working conditions above. The wind tunnel test validates the numerical simulation very well in wind characteristics analysis of parabolic reflector structures by comparisons.

- For most of models with different pitch angles and wind angles, the maximum negative pressure generally appear in the edge region because the incoming flow usually separates significantly at this location. For the model of the same pitch angle at different wind angles, extreme value of the average surface pressure appear at different surface position due to the differences of the separation points position on the wall and the wake effect. In view of the CFD simulation validity for parabolic antenna structure verified by the wind tunnel test, subsequently large scale computations and analysis of different types of reflectors structures are carried out by CFD and the shape factor for each corresponding type of reflector structure under different gestures. This achievement provides abundant wind force proofing design references for those parabolic antennae.

- According to the power spectrum density function it could be seen that the wind induced vibration response of the antenna is a narrow-band course. For the same pitch angle model, the maximum stress power spectrum and displacement power spectrum are highly consistent in the dynamic response of the structure. Although the all-movable antenna structure belongs to such kind of rigid structure, its reflector part has a large span up to one hundred meters more or less resulting in that the structure becomes more flexible. So the effect from fluctuating wind could not be neglected in the wind force proofing design and the first four modes of vibration contribute a lot to wind-induced vibration of the whole structure.

- Under the most unfavorable wind angle $0^{\circ}$, the pitch angles for $5^{\circ}$ and $90^{\circ}$ are two kinds of unfavorable working states because they correspond to the maximal wind pulses of the 
displacement and the stress respectively. Combined with the wind angle and pitch angle, according to the worst upwind attitude, wind pulses could be determined for the all-movable antenna structure in its whole performance. The whole wind pulse of the displacement could be set as 2.5 and 2.2 could be proper for the stress.

- Based on the average wind pressure distribution characteristics and the results of wind induced vibration response, the static wind loads and the corresponding wind vibration coefficient of the reflector are obtained. Taking $110 \mathrm{~m}$ antenna structure $(F / D=0.3)$ as an example, firstly the mechanical analysis under the survival wind speed is carried out and the results show that the whole structure is in the elastic state, the vast majority of members are in the low stress level and all kinds of responses meet the relevant specification requirements. Next, the performance analysis under the working wind speed is carried out. The results show that the antenna structure is more flexible and the wind load takes a leading role on the reflector surface precision.

\section{ACKNOWLEDGEMENTS}

This work was financially supported by the National Natural Science Foundation of China (Grant No. 51378149) and the Natural Science Basic Research Plan in Shaanxi Province of China (Program No. 2016JQ5031).

\section{REFERENCES}

[1] Quattri, Marco., "Proceedings of the International Society for Optical Engineering”, Boston University Press, Boston, 2002, pp. 459-470.

[2] Hiriart, D., Ochoa, J.L. and Garcia, B., "Wind Power Spectrum Measured at the San pedro Martir Sierra”, Revista Mexicana de Astronomia Astrofisica, 2001, Vol. 37, pp. 213-220.

[3] Solari, G. and Piccardo, G., "Probabilistic 3-D Turbulence Modeling for Gust Buffeting of Structures”, Probabilistic Engineering Mechanics, 2001, Vol. 16, pp. 73-86.

[4] Jia, Y.Q., Sill, B.L. and Reinhold, T.A., "Effects of Surface Roughness Element Spacing on Boundary Layer Velocity Profile Parameters”, Wind Eng. Ind. Aerodyn, 1998, Vol. 73, pp. 215-230.

[5] Irwin, H.P.A.H., “The Design of Spires for Wind Simulation”, Wind Eng. Ind. Aerodyn, 1981, Vol. 8, pp. 361-366.

[6] Balendra, T., Shah, D.A. and Tey, K.L., "Evaluation of Flow Characteristics in the NUS-HDB Wind Tunnel”, Wind Eng. Ind. Aerodyn, 2002, Vol. 90, pp. 675-688.

[7] Meroney, Letchford, Sarkar., "Comparison of Numerical and Wind Tunnel Simulation of Wind Loads on Smooth and Dual Domes Immersed in a boundary Layer”, International Journal of Wind and Structures, 2002, Vol. 5, pp. 347-358.

[8] Uematsu, Y., and Tsuruishi, R., "Wind Load Evaluation System for the Design of Roof Cladding of Spherical Domes", Journal of Wind Engineering and Industrial Aerodynamics, 2008, Vol. 96, pp. 2054-2066.

[9] Sterling, M., Baker, C.J. and Quinn, A.D., "Pressure and Velocity Fluctuations in the Atmospheric Boundary Layer”, Wind and Structures, 2005, Vol. 8, No. 1, pp. 13-34.

[10] Kho, S., Baker, C. and Hoxey, R., "The $5^{\text {th }}$ Asia-Pacific Conference on Wind Engineering”, Tokyo University Press, Tokyo, 2001, pp. 509-512.

[11] Chen, Y., Kopp, G.A., and Surry, D., "Prediction of Pressure Coefficients on Roofs of Low Buildings Using Artificial Neural Networks”, Wind Eng. Ind. Aerodyn, 2003, Vol. 91, pp. 423-441.

[12] Launder, B.E. and Spalding, D.B., “The Numerical Computation of Turbulent Flows”, 
Comp. Math. Appl. Mech, 1974, Vol. 3, pp. 35-61.

[13] Canuto, C., Hussaini, M.Y. and Quarterini. A., "Spectral Methods in Fluid Dynamics", Springer-Verlag, 1987, Vol. 12, No. 4, pp. 1473-1490.

[14] Murakami, S. and Mochida, A., "Development of a New Model for Flow and Pressure Fields around Bluff Body”, Journal of Wind Engineering and Industrial Aerodynamics, 1997, Vol. 68, pp. 169-182.

[15] Lin, B., "Application of CFD Simulation Technology in the large Complicated Structure Engineering”, Harbin Institute of Technology, Harbin, 2005, pp. 1-10.

[16] Kato, M. and Launder, B.E., "The 9th Sym. on turbulent shear flow", Tokyo University Press, Tokyo, 1993, pp. 4-16.

[17] Bremer, M. and Penalver, J., “The $6^{\text {th }}$ FE Model based Interpretation of Telescope Temperature Variations”, Bonn, Bonn university Press, 2002, pp. 186-195.

[18] Bremer, M. and Greve, A., "Front and Rear Perspective Heated Prototype Panels for the IRAM 15-m Telescopes in 28th ESA Antenna Workshop on Space Antenna Systems and Technologies”, Netherlands Technology Press, Noordwijk, 2005, pp. 943-960.

[19] Chamberlin, R.A., "Temperature Measurements on the Leighton Telescope”. Surface Memo, 2003, Vol. 5, pp. 124-130. 